$$
\text { ANL/ER/PP- } 83980
$$

\title{
CLIMATE CHANGE EFFECTS ON FORESTS: \\ A CRITICAL REVIEW
}

\author{
Craig Loehle
}

\author{
Environmental Research Division \\ Argonne National Laboratory \\ Argonne, IL 60439
}

and

David LeBlanc

Department of Biology

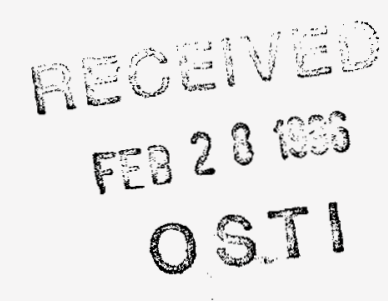

Ball State University

Muncie, IN 47306

DISCLAIMER

This report was prepared as an account of work sponsored by an agency of the United States Government. Neither the United States Government nor any agency thereof, nor any of their employees, makes any warranty, express or implied, or assumes any legal liability or responsibility for the accuracy, completeness, or usefulness of any information, apparatus, product, or process disclosed, or represents that its use would not infringe privately owned rights. Reference herein to any specific commercial product, process, or service by trade name, trademark, manufacturer, or otherwise does not necessarily constitute or imply its endorsement, recommendation, or favoring by the United States Government or any agency thereof. The views and opinions of authors expressed herein do not necessarily state or reflect those of the United States Government or any agency thereof.

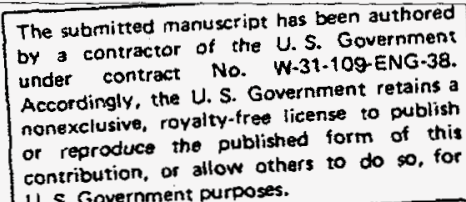




\begin{abstract}
While current projections of future climate change associated with increases in atmospheric greenhouse gases have a high degree of uncertainty, the potential effects of climate change on forests are of increasing concern. A number of studies based on forest simulation models predict substantial alteration of forest composition, forest dieback, or even loss of forest cover in response to increased temperatures associated with increasing atmospheric carbon dioxide concentrations. However, the structure of these computer models may cause them to overemphasize the role of climate in controlling tree growth and mortality. Model functions that represent the influence of climate on tree growth are based on the geographic range limits of a species, predicting maximal growth in the center of the range and zero growth (100\% mortality) at the range limits and beyond. This modeling approach ignores the fact that the geographic range of a species reflects the influence of both climate and other environmental factors, including competition with other tree species, soil characteristics, barriers to dispersal, and distributions of pests and pathogens. These climate-response functions in forest simulation models implicitly assume that tree species occur in all environments where it is possible for them to survive (their fundamental niche or potential habitat) and that these potential habitats are entirely defined by climate. Hence, any alteration of climate must result in a fairly rapid decline of species near their range limits and rapid alteration of forest composition and structure. The climateresponse functions that lead to these unrealistic conclusions have no basis in plant physiology or actual measurements of tree responses to climate stressors. Rather, these functions were chosen as a necessary expedient for modeling the climatic responses of many tree species for which there were limited or no physiological data. There is substantial evidence, however, that some tree species can survive, and even thrive, in climatic conditions outside their present range limits. This evidence suggests that nonclimatic factors exclude some species from natural forests beyond their present range limits and that climate may not be the only determinant of these limits. Hence, there is reason to suspect that published projections of forest responses to climate change based on forest simulation models may exaggerate the direct impact of climate on tree growth and mortality.

We propose that forest simulation models be reformulated with more realistic representations of growth responses to temperature, moisture, mortality, and dispersal. We believe that only when these models more accurately reflect the physiological bases of the responses of tree species to climate variables can they be used to simulate responses of forests to rapid changes in climate. We argue that direct forest responses to climate change projected by such a reformulated model may be less traumatic and more gradual than those projected by current models. However, the indirect effects of climate change on forests, mediated by alterations of disturbance regimes or the actions of pests and pathogens, may accelerate climate-induced change in forests, and they deserve further study and inclusion within forest simulation models.
\end{abstract}




\section{INTRODUCTION}

Concern about the potential effects of climatic warming on forests is increasing (Gates 1990, 1993; Hodges et al. 1992; Overpeck et al. 1991; Perry et al. 1990; Peters 1990; Ritchie 1986; Roberts 1989; Solomon and Shugart 1993; Urban et al. 1993; Woodward 1992). In contrast to agriculture, in which crops can be shifted geographically or new varieties bred in a matter of decades, forests will have a very slow response to climate change because of the size and life span of trees. The effects of climate change on natural forests are unlikely to be ameliorated by human activities to any significant extent. For this reason, it is important to be able to predict likely long-term forest responses to climate change.

Most projections of future climate change associated with increasing concentrations of greenhouse gases in the atmosphere (e.g., Mitchell 1983, Mitchell and Lupton 1984) are based on atmospheric general circulation models (GCMs). Three of the most widely cited GCMs are those produced at the Goddard Institute for Space Studies, the Geophysical Fluid Dynamics Laboratory, and Oregon State University. These computer models divide the Earth into a grid of approximately $5 \times 5^{\circ}$ latitude and model the atmosphere as several horizontal layers. Positions of land and ocean are included, as are the characteristics of the Earth's surface. Cloud cover is also modeled. Within each grid cell, mathematical functions simulate the physical processes of energy and mass transfer. These models generally simulate the present climate of the world reasonably well. However, it is widely recognized that the models are incomplete (they do not simulate all processes) or have weaknesses in specific subcomponents (e.g., cloud processes) (Smith and Tirpak 1989).

Projections of potential climate scenarios from the various GCMs are generally consistent with regard to temperature. All models project increases in global temperature, although the exact amount of increase differs among the models. The models disagree considerably, however, in their projections of future precipitation patterns and the relative balance of water inputs (precipitation) and outputs (evapotranspiration).

The current climate projections from GCMs have two serious limitations. First, the largeness of the grid cells modeled by the GCMs severely limits any evaluation of climate change and its consequences for specific regions. Second, the models themselves greatly simplify complex physical processes that govern climate. The result is that GCMs often disagree on projections of regional climate changes, and their projected climate scenarios cannot be regarded as predictions of future climate (Smith and Tirpak 1989).

In spite of the high degree of uncertainty associated with projections of future climate change, current best estimates suggest that a doubling of atmospheric carbon dioxide $\left(\mathrm{CO}_{2}\right)$ may have the following effects on climate: (1) global mean surface temperature increase from 1.5 to $4.5^{\circ} \mathrm{C} ;$ (2) greater warming at night than during the daylight hours (i.e., increase in minimum temperature but less change in maximum temperature); (3) greater warming during the winter than other seasons; (4) greater warming at higher latitudes than elsewhere; (5) global increase in precipitation, but with substantial regional variations (increases in coastal areas, decreases in continental interiors); and (6) increased summer dryness in mid-latitude continental regions, due to increased evapotranspiration relative to precipitation (see review by Gates [1993]).

With regard to forests, another important component of climate change is the frequency and intensity of extreme weather events such as droughts, hurricanes, wind storms, and lightning. A change in interannual variability, or unchanged variability around a changing mean, would alter the frequency of extreme weather events (Waggoner 1989). While projections of change in climate variability are just as uncertain as other climate projections, some data indicate that increasing mean temperature or decreasing mean precipitation is associated with an increased frequency of extreme weather events (Waggoner 1989; Rind et al. 1989). In an analysis of climate in the midwestern United States, LeBlanc (1993) reported an association between multidecade trends in temperature and the frequency of severe droughts. Ten severe regional droughts occurred during a period of higher temperature extending from 1900 to 1950 , but no droughts of similar severity occurred during a cooler period in the 1960 s and 1970 s. 
Another important consideration is the diurnal and seasonal cycles. For example, if regional warming occurs predominantly during the night, when the stomata of most tree species are closed, the impact of increased temperature on actual evapotranspiration and soil drying will be different from that which would occur if temperatures increase during the daylight hours. Warming at night would increase respiration rates (with consequent reductions in photosynthate for other uses, such as growth or chemical defense), but have less effect on soil water availability than warming during the day. While these effects on respiration and evapotranspiration could both result in reduced tree growth, the relative impacts on tree species with different ecological characteristics may not be the same.

In another example, warming during the winter would likely have a different effect on forests than warming during the growing season. While deciduous trees would likely not be affected adversely by warmer winters, evergreen tree species could experience adverse effects if this warming results in increased evapotranspiration while the soil is still frozen. Also, warmer winters and earlier springs may adversely influence some tree species if this phenomenon interferes with chilling requirements for bud break phenology, flowering, or germination (Cannell 1987). Warming during the winter months may allow northward range expansions of freeze-sensitive tree species and some tree pests or pathogens.

We do not list these various aspects of potential future climate change as predictions. Rather, we describe these projections as a guide to the kinds of environmental change that we might consider when evaluating impacts on forest ecosystems. For example, the current climate projections suggest that impacts on forests will be highly variable among regions. The most adverse impacts on forests of the United States are projected to occur in the Southeast, Great Plains, and Midwest regions (because of increased summer dryness), while forests in coastal regions, the Northeast, and the Northwest may not be adversely affected (Smith and Tirpak 1989). However, these region-specific projections are the most uncertain of the projections derived from GCMs. While all, some, or none of these potential effects of global climate change might actually occur, it is important that we recognize the complex range of possibilities as we evaluate projections of potential forest responses to climate changes.

An underlying assumption in all discussions of potential effects of climate change on forests is that climate exerts a major, if not primary, control over the distribution of tree species, forest types, and biomes, as well as forest ecosystem processes. A huge body of ecological literature supports this assumption. Numerous studies of changes in vegetation along environmental gradients have provided evidence that temperature and soil water availability exert significant control over species distributions and community composition (e.g., Cox and Moore 1980). Past temporal variations in climate have been associated with tree range expansions and contractions. The most dramatic evidence for this observation comes from pollen-based reconstructions of changes in tree species distributions during the Holocene epoch, as glaciers retreated and global temperature increased (Davis 1981; Davis et al. 1986; Webb 1981). More recent tree species range expansions and contractions associated with warming and cooling periods have been documented near the treelines of Scotland and Sweden (Gear and Huntley 1991; Kullman and Engelmark 1991). Hence, the premise that climate change causes changes in tree species distributions and geographical locations of biomes is well founded in historical fact. Climate variables have also been shown to exert significant influence on forest ecosystem processes, including primary production (Mellilo 1993), nutrient cycling (Pastor and Post 1988), and disturbance regimes (Clark 1990; Swetnam 1993; Swetnam and Lynch 1993).

Most published projections of potential impacts of climate change on forest ecosystems are based on the following premises: (1) climate will be warmer and temperature will increase rapidly, (2) climate will be drier in continental regions because of increased evapotranspiration, and (3) climate is the only factor controlling tree species range limits. The latter premise is implicit in all projections that use correlations between current or past tree distribution and climate. Based on these premises, most published projections of forest responses to climate change indicate that there will be large changes in the spatial distribution of tree species and that these changes may be associated with significant tree mortality, forest decline, and loss of forest cover. Tree mortality will be associated with climate-induced reductions in growth. Shrinkage of species ranges and even possible extinction is projected to occur where dispersal of tree species to new regions with suitable climate cannot keep pace with mortality of species in regions where climate is no longer suitable. 
Several approaches have been used to make these projections of likely effects of climatic change on forest ecosystems, including the following:

- Ecological response surfaces that relate vegetation to climate variables, again based on biogeographic correlations (e.g., Lenihan 1993; Overpeck and Bartlein 1989; Zabinski and Davis 1989) and

- Biogeographic correlations between current and past climate and the distribution of tree species and/or forest types (e.g., Emanuel et al. 1985; Guetter and Kutzbach 1990; Woodward 1992);

- Forest simulation models that simulate the growth, mortality, and regeneration process for tree species of specific regions and the impact of changing climate on these processes (e.g., Bonan et al. 1990; Botkin et al. 1989; Dale and Franklin 1989; Solomon 1986; Solomon et al. 1981).

Many analyses have concluded that tree species will not be able to adjust their geographic ranges rapidly enough to remain in equilibrium with a rapid change in climate (Davis 1989; Davis et al. 1986). The projected consequences of this disequilibrium include tree decline and mortality and reduced forest productivity (Bonan et al. 1990; Gates 1990; Peters 1990; Solomon 1986). According to some projections, extinction of some tree species is possible. The fact that analyses based on these different approaches yield similar conclusions has been suggested as evidence supporting the validity of the projections. However, all these approaches are based on the same fundamental assumption: species range limits are determined entirely by climate. In particular, it is assumed that there will be lags in species migrations to new, suitable regions and that trees growing outside their new putative ranges will rapidly die out. Thus, disequilibrium is assumed, but inertia due to tolerance of a novel climate is not (discussed below). These common assumptions may be the primary reason for the mutually supporting conclusions of previous analyses.

All the approaches cited earlier are fundamentally descriptive models that have been empirically fitted to the world as we currently know it or as we infer that it was in the past. Their ability to predict forest composition under present and past climatic conditions has been evaluated with varying degrees of success (Botkin 1972; Davis and Botkin 1985; Solomon et al. 1981); however, these approaches lack the mechanistic functions necessary to explain why trees grow as they do or how they might grow under entirely novel conditions of increased temperature and atmospheric $\mathrm{CO}_{2}$ concentrations (Friend and Shugart 1993; Pacala et al. 1993). Using these approaches to predict forest responses to climate and atmospheric conditions that are different from any in the past is not unlike using site index curves developed for one tree species and region to estimate site index for a different tree species or for trees in a different region. While the broad patterns of such predictions may be more or less correct, the size of the prediction errors is entirely unknowable and may be large. Forest simulation models that include a more mechanistic, physiological treatment of the way climate factors influence tree growth are currently being developed (e.g., Friend and Shugart 1993), but they have not yet been applied to project forest responses to climate change.

Our objectives in writing this paper are as follows:

- To summarize the literature pertaining to projections of forest responses to climate change, focusing on the underlying assumptions of these analyses and the impact of these assumptions on projections of forest responses;

- To discuss the major physical and biological factors and processes that may be important determiners or mediators of forest response to climate change; and

- On the basis of this review, to suggest new areas of research and modifications to forest simulation models that might increase their ability to make valid projections of forest responses to climate change. 


\section{APPROACHES FOR PROJECTING FOREST RESPONSES TO CLIMATE CHANGE}

Various approaches have been used to assess the likely response of forests to climate change (Bonan et al. 1990; Botkin and Nisbet 1992; Dale and Franklin 1989; Davis and Botkin 1985; Emanuel et al. 1985; Pacala and Hurtt 1993; Shugart et al. 1992; Solomon 1986; Solomon and Bartlein 1992; Zabinski and Davis 1989). The three primary approaches are ecological response functions, biogeographic correlations between climate and tree species or forest type distributions, and forest simulation models. We begin our analysis by reviewing these three approaches.

\section{II.A. Ecological Response Surface Models}

In ecological response surface models, the abundance of tree species or their pollen in bog or lake sediments, measured at a large number of sites, is used to calibrate a multiple regression function of tree or pollen abundance versus various climate variables (Lenihan 1993; Overpeck and Bartlein 1989; Overpeck et al. 1991; Webb 1992). Generally, a well-defined response surface can be obtained that predicts the geographic range and local abundance of the species with a high degree of accuracy (correct classification of 80-97\%). Overpeck and Bartlein (1989) analyzed the effects of climate change on forests of eastern North America by using response surface models, and they concluded that "even slight climatic change can have a significant impact on natural vegetation."

Response surface models have been applied to paleopollen data to reconstruct forest history in response to past climate changes. As Watts et al. (1992), Webb (1986), and Prentice (1986) document, pollen sample dating and spatial resolution difficulties make such uses of pollen data suspect, in most cases, for periods of less than 500-1,000 yr and distances of less than 100-200 mi, which is the time and space scale of interest for greenhouse-type climate change impacts. A second difficulty is that distortions in past species composition currently attributed to migration lags (e.g., Davis 1989) may well result from individualistic responses to shifts in relative seasonal weather patterns, as documented by Webb (1986). The resolution and interpretation of paleoclimate-vegetation change studies is thus not yet reliable enough to extrapolate to future climate change effects on forests, particularly at regional scales and for short (100-200 yr) time periods.

The ecological response surface method suffers from an even more fundamental difficulty, however. Because what is measured is the abundance of a species as a function of current climate, the effects of competition are confounded with the response to climate. As is demonstrated later, trees are often capable of growing far outside the range of conditions where they are dominant. This is the difference between the fundamental and the realized niche: the fundamental niche is where the plant can grow in the absence of competition, whereas the realized niche is where the plant is found in communities where competition is active. The fundamental niche is what governs the actual growth of plants, whereas the realized niche is an abstract concept obtained by correlating species abundance with abiotic factors. Plants may actually grow best outside their realized niches but be excluded from favorable sites by competition (e.g., lodgepole pine [Pinus contorta] is found only in very cold or dry sites, but grows best in mesic, warm sites).

It is not possible to draw any conclusion about the fate of existing trees and stands from an ecological response surface analysis; only the equilibrium situation (the communities that would exist following a prolonged period under the new climate) can be predicted. No prediction can be made about the nature or duration of the transition period to a new forest-climate equilibrium (Malanson 1993). The estimate made by Overpeck and Bartlein (1989) that equilibrium would be reached in 100 $200 \mathrm{yr}$ is external to the ecological response surface model and is speculative. We need to justify an estimate of time to equilibrium and to quantify the dynamics likely to occur during the transition from current to expected vegetation (i.e., dieback versus gradual species replacement). Only stand growth models that simulate growth processes allow us to quantify likely transient responses.

Because the ecological response surface method uses correlations based on the realized niche rather than the fundamental niche, there may also be a problem with the species range changes predicted by this approach. Because the realized niche is a joint function of the fundamental niche and the effects of competition, it is impossible to separate these two factors without further information. 
The competition effects that yield the realized geographic range are not directly observable or manipulable and are therefore hidden parameters of the model (sensu Loehle 1987). Since climate change will shift species ranges differentially and expose species to new combinations of competitors, the realized niche that results from any given novel climate will likely differ as the mix of competing species changes. Thus, projections of abundance over the landscape following major climate changes are questionable. In contrast, competitive interactions are, or can be, represented more explicitly in a forest simulation model such that the effect of new combinations of competitors can be modeled.

The response surface approach assumes that the factors used to predict species or pollen abundance will remain predictive in the future, but because current models are empirical and not mechanistic, predictions for novel combinations of climate factors may not be possible. The factors used in the regressions may currently be correlated with factors that truly govern tree distribution, but the relation between various climatic factors is likely to shift with a climate change. For example, at 6,000 Before Present (B.P.), winters were relatively colder than today and summers were relatively warmer. A paradoxical result of trends after 6,000 B.P. was that in the southern Quebec area, spruce (Picea) moved south and beech (Fagus) moved north (Webb 1986). Under projected greenhouse warming, winters, particularly in the north, will warm the most. Thus, either for projections into the future or applications to the past, it is not safe to assume that a warming or cooling trend simply causes a movement north or south of existing climatic zones. That is, future climates are, in fact, likely to be novel with respect to what we observe today, and this circumstance will likely shift competitive relations and invalidate abundance predictions. Because of this, only response functions that truly capture the physiological limitations of a species can provide valid projections, and even then perhaps only predictions of the species range limits (not abundance).

The result of past and future climates having different configurations (being novel) and the complications resulting from the use of the realized niche (observed abundance) causes difficulties in testing response surface models. Lack of fit of predicted ranges for paleodata is often explained away as disequilibrium due to limitations on migration rates. Webb (1986), however, argues that most such disequilibrium responses (lags) actually represent individualistic species responses under novel climates. To distinguish lags from individualistic responses, response surface predictions for past climates must be tested with detailed climate data (seasonal patterns, day-night differences, variability) rather than with mere estimates of past mean temperature deviations. Because such data have not been available, it is not possible to say that response surface approaches have been validated by their applications to paleodata. Until they have been validated in this way, the objections of Webb (1986) stand, and we must remain suspicious of the application of these approaches to novel climates, including future greenhouse climates.

An additional difficulty concerns the fact that climate-response function models generally ignore topography/microclimate as a predictive factor and in applications to future climates. The abundance of a species over its range, which is used as input to derive the response surface regressions, may be governed largely by topographic factors and may therefore lead to a misleading predictive model.

An example illustrates the difficulties. American beech ( $F$ agus grandifolia) currently grows from Nova Scotia to the Gulf of Mexico. Over this range, however, it does not grow on all sites. In the Southeast, in particular, it tends to grow largely in ravines and near small creeks. It cannot tolerate droughty or waterlogged soils, prolonged flooding, or frequent burning; however, it can be found in the few locations in central Florida where there is some topographic relief. Under a warmer and drier climate, such stream valley sites will still be common in the Appalachians, where elevation also creates cooler and moister conditions, as well as in dissected terrain in the Southeast, such as the Piedmont region. Thus, it seems exceedingly unlikely that the Zabinski and Davis (1989) prediction, based on climate-response functions and a doubled $\mathrm{CO}_{2}$ environment, that beech will be restricted to a zone north of the Great Lakes is in any way realistic. Their prediction is in error because of the failure to include topography and the implicit assumption that the abundance of a species in an area is exclusively the result of the climate in that area. In contrast, gap-phase models for the Pacific Northwest that include topography have predicted local shifts in abundance, along topographic gradients, but no regional extinctions (Urban et al. 1993). Thus, the catastrophic range shrinkages predicted by Zabinski and Davis (1989), and widely cited by others, for hemlock, beech, sugar maple, 
and yellow birch are most likely artifacts of these deficiencies. It is possible to create response surface models that incorporate topography to create more realistic predictions (e.g., Running and Nemani 1987), but studies to date have not done so.

A final caution in the use of response surface models to examine paleoperiods is that for the period since the last glacial maximum, fossil leaves imply that leaf stomatal conductance has gone down as $\mathrm{CO}_{2}$ levels have gone up, indicating increased efficiency of water use over this period (Beerling and Woodward 1993). This effect has not been incorporated into response surface models. The same caution applies to the use of these models for projecting future changes, because $\mathrm{CO}_{2}$ levels will continue to rise in the future. Because these models are not mechanistic, it will be difficult to incorporate $\mathrm{CO}_{2}$ effects into them.

We conclude, therefore, that the response surface approach is fundamentally flawed with respect to the prediction of tree species responses to past and future climates because it is based on the realized niche, it fails under novel climates, it says nothing about transient responses, it does not include $\mathrm{CO}_{2}$ effects, and it does not include topographic/edaphic factors.

\section{II.B. Biogeographic Correlations}

A second type of predictive model for examining climate change effects uses correlations between regional climate conditions and the spatial distribution of vegetation types (Guetter and Kutzbach 1990; Monserud et al. 1993; Prentice et al. 1992; Woodward 1992). Biogeographers have long described vegetation on the basis of correlations with climate. That a certain combination of precipitation and temperature will yield a desert or tropical rain forest is well established. Even specific types of vegetation can be classified in this way. Thus, taking a classification that fits today's vegetation and applying it to the climate predicted for the future is straightforward. Several such studies (Emanuel et al. 1985; Guetter and Kutzbach 1990; Monserud et al. 1993; Woodward 1992) have found that major shifts in ranges of biomes or biotopes are likely. (A biotope is the smallest geographical unit of the biosphere or of a habitat that can be delimited by convenient boundaries and is characterized by its species composition.) The projected rates of geographic shift are greater than the likely migration rates of constituent species, suggesting a potential for significant dieback in these communities.

The biogeographic correlation approach again suffers from the problem of using the realized niche when the fundamental niche is needed-this time on the scale of communities rather than individual species. The approach shows what community type is expected under a given climate but does not indicate what is likely to happen to existing community types under a shifting climate. It is not at all clear for, example, that following a warming of a few degrees, a particular community (that is, all of its constituent species) should necessarily die off catastrophically. Instead, it may be that the replacement of one community by another would occur over a prolonged period, as noted by Monserud et al. (1993).

There are other problems with the biogeographic correlation approach. First, the nonoverlap between current biotopes and those predicted to occur under a changed climate seems to imply that the old ecosystems will suffer catastrophe in these zones, although this implication is not explicit as it is in the ecological response surface approach. The data on fundamental niche widths and on species tolerance of climatic fluctuations (discussed below) suggest that catastrophic consequences do not necessarily follow, however. For example, a grassland system under a wetter climate will not suffer extinction but will be replaced by trees following a long lag period.

Second, the implication is that biotope range changes are analogous to species range changes, which means that when a biotope is replaced by another, all the species in the biotope change. In reality, many species overlap between adjacent biotopes. In a zone experiencing warming, for example, many of the species that will dominate in the new biotope may already be present in specialized habitats within the current biome (e.g., if the transition is from woodland to prairie, many prairie species are already present in the woodland understory). In general, species tolerant of drier conditions are usually present as early successional species, or they occur on dry microsites of an otherwise more mesic biotope. Thus, a change in biotope does not represent a complete replacement of all species, as it might appear to do at first glance. 
Third, if biotypes are defined by annual means but warming is likely to be greater in winter (as projected by GCM calculations), then predicted changes in lifezones will be much too large (Rowntree 1985), particularly in northern zones. Changes in seasonal temperature distributions (i.e., novel climates) may also invalidate existing lifezone classifications.

This examination of correlational approaches to predicting forest response to climate change, and their underlying assumptions, leads us to conclude that their projections are, at best, first approximations of forest response to climate change. The dangers of extrapolating statistical association beyond the range of data used to derive them are well known. These dangers are even more worrisome when there is limited knowledge of the biological and ecological mechanisms that are believed to cause the statistical association. We believe that meaningful projections of forest response to climate change can come only from a mechanistic, process-oriented modeling approach. This leads us to an examination of forest stand dynamics models.

\section{II.C. Forest Stand Simulation (Gap) Models}

Forest stand simulation (gap) models of the JABOWA (Botkin 1972) and FORET (Shugart 1984) design are widely used tools for assessing climate change effects on forests (Bonan et al. 1990; Botkin et al. 1989; Dale and Franklin 1989; Prentice et al. 1993; Solomon 1986; Solomon and Bartlein 1992; Solomon and Webb 1985). These models simulate the establishment, growth, and mortality of individual trees within small plots (approximately $0.1 \mathrm{ha}$ ). They integrate species-specific information regarding the influence of age, light, nutrient availability, water availability, and temperature on tree growth. The effect of differential height growth on between-tree competition for light is explicitly modeled at the individual tree level. Each species is assigned an age-related maximum growth rate, which is then reduced by response functions that represent environmental limitations (light, nutrients, water, and temperature). In simulating the effects of disturbances, tree mortality is modeled as a stochastic process with two parts: (1) intrinsic probability of mortality, determined by expected longevity for each tree species, and (2) extrinsic probability of mortality, determined by growth rate (decreasing growth increases the probability of mortality). The death of a tree releases space for new trees to grow or opens understory trees or seedlings. Seedling establishment is modeled as a stochastic process; the seeds for all tree species included in the model are able to reach all plots. However, the subsequent survival of the seedlings is constrained by the environmental conditions that limit tree growth and survival. A forest is simulated by modeling a large number of plots or "gaps" (hence the name gap model). Shugart et al. (1992) review individual-based forest simulation models and their application to projecting forest responses to climate change.

Results from forest simulation models suggest that climate change could have substantial impacts on the forests of North America, including diebacks of tree species, alteration of forest composition, altered nutrient cycling and productivity, and, in some cases, even complete loss of forest cover. Varying subsets of these projections have been made for forest types across a wide geographic range, including the northern boreal forest of Alaska (Bonan et al. 1990), the southern boreal forest (Pastor and Post 1988), the northern mixed conifer-hardwoods forest of Michigan (Botkin et al. 1989; Solomon and Bartlein 1992), southern pine forests (Urban and Shugart 1989), southeastern hardwood forests (Solomon 1986), and coniferous forests of the Pacific Northwest (Dale and Franklin 1989; Urban et al. 1993). In many of these simulations, a transition period or "transient" is identified. This is a period of rapid climate change and reduced forest productivity and biomass, including large-scale diebacks. These alterations in forests are associated with a time lag between the decline of tree species unable to adapt to a warmer, drier climate and the immigration of new species that are adapted to the climate. However, extant forest growth models have not necessarily been tested adequately for transient conditions. An examination of model assumptions and historical data in fact indicates that there is reason to question their predictions for transients (discussed below).

\section{II.C.1. Forest Gap Model Testing}

Forest simulation models have been tested in a number of ways. It has been demonstrated that these models can predict proper successional progressions and overall forest species compositions, gap size distributions, and tree size distributions for extant forests (Botkin 1972; Solomon et al. 1981). Model simulations of temporal changes in tree species distribution and forest composition during the 
period after the retreat of the last continental glacier have been shown to broadly correspond to pollenbased reconstructions of forest composition during this period (Davis and Botkin 1986; Solomon et al. 1981). However, the same pollen data used to reconstruct past forest composition were also used to reconstruct the historical climate inputs used by the forest simulation models (Shugart et al. 1992). As previously discussed, pollen data have time and space resolutions of $\pm 1000 \mathrm{yr}$ and $100 \mathrm{mi}$ (Watts et al. 1992; Prentice 1986, Webb 1986). Also, tests of the models often allow the forests to reach relative equilibrium with climate (Malanson 1993). To understand the policy implications of projected changes in species ranges, however, forest dynamics in the near-future (next 100-200 yr) at a scale of 100-200 mi and with disequilibrium conditions may be of the greatest interest. Because forest stand simulation models have not been tested under these conditions, some caution is appropriate when using them for predicting near-future climate change effects on forests.

A general problem in assessing forest stand models is finding an acceptable criterion for validation. For example, the fact that all three methods reviewed here broadly agree on the likely long-term changes in vegetation suggests that their predictions may have validity for equilibrium conditions as long as future climate regimes are not novel. This agreement does not, however, verify the models, mechanisms or predictions for transient conditions, because their agreement is strongly conditioned by their common basis in associations between current geographic ranges of tree species and current climate zones. Shugart et al. (1992) pointed out a danger in "testing" the models against historical data because vegetation (pollen) data have, in some cases, been used to derive this data. Historical climate data for such testing should be derived from some other source, such as isotopic measurements of cave deposits or ice cores.

Sensitivity analyses have suggested that an estimation error of $10 \%$ in JABOWA model parameters caused little or no change in modeled forest response to global warming scenarios (Botkin and Nisbet, 1992). This result was taken as evidence of model reliability. Properly speaking, however, model insensitivity to parameter estimation error indicates robustness, but not accuracy or correctness. A very "robust" model can be devised (e.g., a predator-prey model with a stable equilibrium point) that is insensitive to parameter error in terms of outcome but is unrelated to the real world in terms of its behavior. In particular, prediction errors resulting from improper model formulation cannot be tested with sensitivity analyses. Differences between models with different formulations represent hidden parameters because no parameter in one model can be tuned to yield the other model (Loehle 1987). Such differences are structural; they cannot be revealed by sensitivity analysis, but only by explicitly comparing alternative models.

Finding that a model is insensitive to parameter error is reassuring only if we are confident that the model is formulated properly and if we have tested it against complete test data. As noted earlier, neither of these conditions applies in the case of forest simulation models. Few verificatory tests of transient dynamics under nonequilibrium climate have been conducted with these models. Critical aspects of model formulation, including the mortality function and the growth functions for temperature and moisture responses, are questionable. In particular, the biases introduced by the model limitations are all in the direction of overestimating the sensitivity of trees to changing climate conditions. Thus, not only are the parameter errors hidden structural parameters, but they are additive in their effect, rather than independent as assumed by a sensitivity analysis. In fact, the growthresponse bias that leads to slow growth is amplified by the extra sensitivity of the mortality function to slow growth (discussed below), which causes these two biases actually to be multiplicative. This phenomenon was not evaluated by Botkin and Nisbet (1992), and it could easily lead to effects that exceed the $10 \%$ parameter errors they investigated. A closer look at model formulation is therefore warranted.

\section{II.C.2. Analysis of Forest Simulation Model Assumptions}

For accurate projections of transient response, certain details of the stand models may require reformulation. Three functions that could be causing difficulties are dispersal, mortality, and growth. It is noteworthy that all three of these functions, as currently formulated, bias the results toward more sensitivity to climate change. 


\section{II.C.2.1. Dispersal}

Dispersal has traditionally not been modeled explicitly in stand models. Rather, all species in the model are assumed to be available at all sites. As a result, the lag in the arrival of more southern species is, very simply, eliminated. When coupled with excessively pessimistic predictions of mortality, this omission leads to very rapid displacement of existing vegetation following warming. It is, of course, recognized that dispersal is, in fact, a limiting process. More recent models under development are beginning to model dispersal explicitly (Pacala et al. 1993); we do not discuss it further here.

\section{II.C.2.2. Growth Functions}

The parameters that govern growth responses at geographic range boundaries (particularly southern or drier boundaries) are critically important because the models predict that major impacts of climate change, such as dieback of stands will occur there. Examination of model structure shows that the temperature and moisture growth-response functions are critical determinants of projected geographic boundaries in simulations of forest response to climate change. The temperature-response function is a simple parabolic curve that predicts maximum growth at temperatures found near the north-south midpoint of the geographic range of the species; growth falls to zero at temperatures found at the northern and southern range limits. The result of a very low or very high temperature is a very low growth rate, which leads to tree death. The moisture-response curve reflects a linear negative association between tree growth and the number of drought days per growing season (determined from precipitation and potential evapotranspiration data).

By using climate conditions at species range limits to parameterize climate-response functions, forest simulation models confound the influences of climate and other environmental factors that determine range limits, particularly competition. This response function formulation does not represent the influence of climate on the ability of a tree species to grow and survive, but rather the influence of climate on the ability of the species to compete successfully against other species. While a model formulated in this manner yields a good match to observed forest composition, it does not reflect biological reality with respect to tree growth in the absence of competitors whose ranges do not currently overlap.

Several studies based on ecophysiological models and/or tree growth-climate correlation analyses have demonstrated that the climate variables and/or response functions used in forest simulation models are not adequate (Cook and Cole 1990; Bonan and Sirois 1992; Nikolov and Fox 1994). Denton and Barnes (1987) found that the distributions and range limits of tree species in Michigan were correlated with a large number of climate variables, including both means and variances that represent climate at annual, seasonal, and diurnal time scales. Climate variables that were highly correlated with tree species distributions included growing season temperature and length, night temperature, precipitation relative to potential evapotranspiration, and heat sums prior to last spring freeze. While the simple annual growing degree-day and drought-day sums used in many forest simulation models may well be correlated with some of these more detailed climate variables now, there is no assurance that such correlations would hold under novel climates that might occur under global warming.

Bonan and Sirois (1992) used an ecophysiological model to evaluate the effects of temperature on the photosynthesis of black spruce (Picea mariana). Their analysis concluded that (1) the northern range limit of this species is not determined by the direct effects of low growing season temperature on growth and (2) that growth is optimal at temperatures that currently prevail at the southern range limit of this species. Bonan and Sirois cited a number of studies of other boreal tree species that also found that boreal trees grow best at their southern range limits and are able to grow well in gardens far south of their range limits. Bonan and Sirois concluded that forest simulation models simulate stand-level responses to geographic variation in climate that agree with observed forest patterns, but that the model outcomes occur for the wrong reasons. That is, the model is based on the assumption of a direct physiological response to temperature, when observed variation in forests along temperature gradients may reflect the interaction of temperature and other factors.

Nikolov and Fox (1994) also used a physiologically based modeling approach to evaluate the relationship between climate and tree growth. They observed that there was no direct correlation 
between the growth of three western coniferous tree species and growing degree-days, the primary representation of temperature in forest simulation models. Rather, tree growth (net carbon gain) was more highly correlated with irradiance, humidity, and soil water; temperature accounted for only $17 \%$ of the variation in growth. At best, growing degree-days were found to be a good indicator of plant respiration losses only. Nikolov and Fox concluded that current forest simulation models are not capable of projecting forest ecosystem responses to environmental change, mainly because of the overly simplistic climate-response functions. These response functions fail to link annual growth (and mortality) to subannual patterns of carbon, water, and energy utilization by trees.

Cook and Cole (1990) used dendrochronological analyses to determine the correlation between climate variables and radial growth of eastern hemlock (Tsuga canadensis) at numerous sites distributed across its entire geographic range. Dendroclimatological analyses for sites near the northern range limit of the species found no evidence that growth was limited by low temperature. Rather, hemlock radial growth was negatively affected by high temperatures during the prior growing season at sites across its range (including sites near the northern range limit). Growth was positively correlated with prior growing season precipitation (after the effect of local site drainage was accounted for). Hemlock radial growth was also strongly positively correlated with March temperature across a wide geographic range. These results are consistent with the assumption in forest simulation models that the southern range limit is related to an interaction of high temperature and water stress. The mechanism for the positive correlation between growth and March temperature is unclear, although it may be related to the depth of snow and length the of growing season. Thus, a warmer climate could produce countervailing influences on eastern hemlock growth (negative effect of increased growing season temperature vs. positive effect of increased March temperature, possibly resulting in a longer growing season). These complex relationships between the radial growth of eastern hemlock and temperature are not currently represented in forest simulation models. They highlight the need to explicitly consider the effects of a warmer climate on both growing season climate and length of growing season.

Another study of the distribution of eastern hemlock near its northern range limit supports the contention that this limit is not determined by temperature. Kavanagh and Kellman (1986) found that eastern hemlock near its northern range limit attains its highest importance on steep north- and westfacing slopes. This finding directly contradicts expectations that eastern hemlock is limited by low temperature at its northern range limit. In fact, growth rates of eastern hemlock in populations at the northern range limit and populations in the center of the range were not significantly different. The only difference observed between the northern populations and populations near the center of the range was that recruitment was more episodic at the northern range limit and more or less continuous near the center of the range. Kavanagh and Kellman (1986) concluded that competition or fire frequency (average 80-yr return time in the Canadian Shield area boreal forest) may be more important than climatic factors in limiting the northern extent of eastern hemlock.

Although eastern hemlock is probably not representative of all tree species, the fact that detailed analyses of growth-climate relationships for this species discredit climate-response algorithms in widely used forest simulation models should serve as a caution. Granted, eastern hemlock is an ecologically and physiologically complex species, occurring across a wide range of site types (mesic to xeric, acidic to basic soils) and with morphologically and ecologically distinct ecotypes (Kessel 1979). Nonetheless, eastern hemlock is one of the first species for which a detailed spatial analysis of growthclimate relationships has been implemented across its entire range. Similar unexpected growth-climate relationships may not be found for all other tree species, but until similar studies have been done for other tree species, care should be exercised in the interpretation of forest responses to climate change as modeled by FORET-type simulation models. Such models can be modified to include topography/edaphic factors, but such modifications generally require a much more mechanistic approach.

Additional evidence in support of this criticism of the simple climate-response functions in forest simulation models can be found in the widespread planting of tree species beyond their natural range limits. Many tree species can be planted one to several hundred miles north or south of their natural ranges (e.g., in plantations, Christmas tree farms, and residential plantings) (Guilding 1825; Wright 1976). For example, the natural range of white spruce (Picea glaucia) only extends down to 
the southern margin of the Great Lakes, but in botanical gardens, it can be found as far south as the southern foothills of the Appalachians (Loehle, unpublished data). There are redwoods growing in Atlanta and palm trees on the University of Washington campus (Loehle, unpublished). Because frost damage is a more severe limitation than heat stress, such plantings are usually possible farther south of the natural range limit than north of it. Wright (1976) cited a number of studies that showed that only when trees from the northern Untied States were planted nearly $1,000 \mathrm{mi}$ south of their native range along the Gulf coast (with irrigation) could any failure to grow be observed that was due directly to temperature. In some cases, trees at the southern margins of their ranges may grow faster than over the rest of their range, and they may actually exhibit a positive response to warmer periods (e.g., Bonan and Sirois 1992, Kauppi and Posch 1985). These cases would indicate that the growth of these trees is not limited by temperature beyond their southern range limit, but rather that they probably cannot compete successfully against other species that occur in warmer climates. Tested against these data, forest stand models fail, because simulated trees die outside their normal geographic ranges. The true growth function clearly has a wider spread than those used by models (Bonan and Sirois 1992). This observation may generally be true for tree species whose distribution is significantly limited by competition with species that are more shade tolerant, more rapid growing, or larger (Figure 1).

A crucial assumption in the calibration of climate-response functions in the forest simulation models is that the geographic range limits are governed by climatic variables, such as summer and winter temperatures. For trees in the eastern United States, however, the southern and western range limits may not result strictly from nonoptimal temperature and moisture. Many species have ranges that extend all the way to the Gulf of Mexico but not into Florida (Quercus alba, Q. phellos, Salix nigra, Tilia heterophylla, Fagus grandifolia, Fraxinus pennsylvanica, Juglans nigra and others [Fowells 1965]). The fact that most of these species do not grow in Florida or grow only in the very northern edge of Florida could be taken as an indication that they cannot grow farther south, but such a conclusion may not be warranted (Gates 1993, p. 137). The entire peninsula of Florida has very adverse physiographic conditions. Soils are either sand or hydric, and they tend to be very nutrient poor. Many species could be excluded from Florida because of these soil conditions rather than because of temperature. Thus, geographic range limits do not necessarily indicate whether these species could tolerate conditions several hundred miles farther south, or, equivalently, several degrees warmer. This situation calls into question the near-deforestation of the Southeast predicted by Urban and Shugart (1989). A similar observation was made by Lenihan (1993), who indicated that while climate was the primary determinant of the geographic distribution of boreal forest tree species, regional differences in substrate conditions were also important in explaining differences in distributions of some tree species.

Just as northern and southern range limits are not necessarily controlled by temperature, western range limits of tree species may not necessarily be determined by water availability or drought days. Tree growth west of the Mississippi may have been historically limited by fire as well as by lower water availability. That is, some tree species can grow quite well far west of where they were historically found, in regions where they were historically excluded by frequent fires. In calibrating a growth model, we must base the growth function on actual growth and include competition and disturbance as separate factors. Combining these factors confounds the processes (Loehle 1987) and produces unrealistic growth responses when nonequilibrium conditions are simulated.

Existing forest simulation models give a reasonable prediction of outcome within the normal geographic range, even though the mechanisms are modeled crudely, because during competition in a growing stand of trees, small inequalities in growth rate are amplified. If a tree grows just slightly more slowly than its neighbors, it will be overtopped within a few years and die for lack of light (if it is shade intolerant). Once trees are overtopped, the initially more or less symmetric competition between neighbors becomes grossly asymmetric. The outcome for the loser is equivalent to having a zero growth rate in the given environment because no trees of this species will reach maturity. Thus, under equilibrium climate and in the presence of competitors, model outcomes closely parallel observations of existing forests. This observation affects the interpretation of any sensitivity experiments with these models because the model will not be sensitive to the shape of the growth curve in the presence of competitors. 
Climatic warming, however, is a nonequilibrium situation in which the fundamental niche (where a species can grow) and the realized niche (where a species actually grows in the presence of competitors) do not give equivalent transient dynamics. The geographical limits of the fundamental niche will vary immediately in response to a change in the physical environment, while a change in the limits of the realized niche requires time for mortality of established trees and migration of competitor species into the regeneration pool. Changes in the geographic limits of the fundamental niche may mean little to the species involved, since the species may not exist at these limits because of competitive exclusion by other tree species. For example, experiments on a model of chaparral responding to increased precipitation showed that use of the fundamental niche gave more continuous cover (no diebacks), lags in vegetation change, and different dominance patterns than use of the realized niche (Malanson et al. 1992). As another example, if the fundamental niche (temperature growth response) of species $\mathrm{Y}$ is wider than the parabolic realized niche function based on geographic range, and if the trees grow in a single-species stand, they will grow according to the fundamental rather than the realized niche, which means that under climatic warming, they will not necessarily die and may even grow faster (e.g., Bonan and Sirois 1992; Kauppi and Posch, 1985). Only when competing species with a faster growth rate under the new climate regime are present will the abundance of a species begin to decline because of failure to reproduce or to reach reproductive maturity. Existing canopy trees will not necessarily suffer; thus, an inertia in species composition may be exhibited (discussed below).

\section{II.C.2.3. Mortality Responses}

A wide range of tolerance to climatic fluctuations is exhibited by trees. Some species, such as bristlecone pine (Pinus aristata), northern white cedar (Thuja occidentalis), and eastern red cedar (Juniperus virginiana), can tolerate extremely slow growth indefinitely, surviving in spite of ring widths that are barely measurable. Other species can tolerate extreme growth suppression only when young. Most long-lived species can tolerate a few to many years of slow growth, especially if they are canopy dominants. On the other hand, older trees and many early successional species (those with short life spans) will die rapidly if their growth rate falls below some minimum. The mortality functions in forest simulation models do not represent these diverse responses. In the models, basic mortality is a constant probability based on life span, which gives a negative exponential survivorship curve. As trees get larger, their modeled growth rate decreases. If growth falls below some minimum (because of size or climate), the probability of mortality is enhanced. Because this threshold is constant for all species, all species are treated like early successional types that are intolerant of growth reduction.

As Pacala and Hurtt (1993) noted, however, this type of mortality function is not realistic. Not only does such a function often fail to represent the tolerance of climatic fluctuations exhibited by many species, it also amplifies the rate of mortality that results from climatic-warming-induced growth suppression. Because the modeled growth suppression resulting from warming is itself exaggerated when the current species range limits are used to parameterize the climate-response function, the result is greatly enhanced mortality rates due to warming at the southern margin of species ranges. These model deficiencies were not noted in earlier studies because such extreme effects do not occur when the forest is modeled as being in equilibrium with climate. In addition, these enhanced mortality effects are not noted when calibration is based on the equilibrium composition of the forest. In particular, the output variables for model testing are typically forest composition variables and tree size distributions, not the details of mortality (which trees died and what caused their deaths). Under a changing climate, however, tolerance of periods of adverse conditions, and especially differential tolerance of growth decline among species, becomes very important for modeling transient dynamics correctly.

\section{II.D. Expected Rates of Vegetation Change}

Given the foregoing discussion of the ways in which extant models are deficient, it is necessary

to ask what response we may in fact observe following warming and what historical data we might bring to bear to evaluate likely rates of change. We may invoke the concept of vegetation inertia to help us in considering this question. Vegetation inertia is the tendency of a vegetation type, once 
established, to maintain itself. Inertia results from (1) longevity of individuals and their tolerance of climatic variability, (2) effects of the established community on abiotic factors (e.g., fire, litter type, soil moisture), and ( 3 ) seed rain advantage of established plants (consider that even with a significant growth rate advantage, an initially rare species is still outnumbered 1,000 or more to 1 at the seedling stage). At treeline, for example, clusters of trees that become established will persist for long periods, and the border between trees and alpine herbaceous plants will be quite stable over time. At the Cedar Creek Long Term Ecological Research site in Minnesota, grasslands on abandoned farm fields surrounded by forest have shown very little invasion of forest over periods as long as $70 \mathrm{yr}$, even though fire has been excluded. Basswood (Tilia) in northern England currently reproduces only vegetatively and may be a relict of a warmer period several thousand years ago (Pigott 1981, Pigott and Huntley 1981). Many other examples of the inertia of established vegetation also exist.

The inertia of a forest in response to climate change cannot readily be tested with extant forest growth simulators because of the deficiencies noted earlier. However, paleodata are available that show what appears to be strong inertia to change in plant community composition. Cole (1985) provides one of the more substantive examples. Cole analyzed plant species found in fossil packrat middens from the eastern Grand Canyon. Following the Pleistocene-Holocene boundary (between 11,000 and 10,000 B.P.), when temperature rose by at least as much as is projected for climate warming scenarios, there was a very protracted change in species composition. Over a period of about a 2,000 yr many Wisconsin species were lost, and the total number of species dipped. This was hardly a catastrophic or sudden dieback. The loss of northern species was followed by a lag of about 1,000 $3,000 \mathrm{yr}$ before the arrival of Holocene dominants. Overall, the transition to a modern plant community took about 5,000 yr. Cole (1985) interprets this as the initial loss of only those northern species at the edges of their ranges, with other northern species disappearing gradually by competitive displacement following the arrival of Holocene species; here "gradually" means over a period of several thousand years.

The gradual change observed at the Grand Canyon following a sharp rise in temperature may, in fact, be a general response. Nonvegetational paleoclimate studies in the northern hemisphere seem to indicate that a dramatic rise in temperature substantially precedes any evidence of change from vegetational records (Mercer 1972). Coleopteran assemblages from Great Britain have been interpreted as showing a sharp rise in temperature between 14,000 and 13,000 B.P., several thousand years before any indication of change in pollen records (Coope 1977). Cwynar and Spear (1991) studied spruce forest pollen and macrofossil records from lakes in the Central Yukon, in an area where forest was patchy and thus dispersal was not limiting. They found about a $500-$ to $1,000-y r$ lag for forest spread following the initiation of a warm period (warmer than today) that began about 10,500 B.P. and at least a 500 -yr lag in forest reversion to tundra following the return to cooler conditions at about 5,500 B.P. Ground vegetation remained unchanged over this period. This scenario is consistent with our earlier argument that trees at their northern limit should be limited more strongly by temperature and will respond (decline) more abruptly following a cooling than they will expand following a warming. Campbell and McAndrews (1993) documented changes in mixed forest in southem Ontario. Following Little Ice Age cooling of about $2^{\circ} \mathrm{C}$ beginning in about A.D. 1200 , about $300 \mathrm{yr}$ was required for decline of the more warmth-loving dominant American beech. Gates (1993) documents a rapid southward retreat following the Younger Dryas cooling, with a more gradual advance upon warming.

To summarize these studies, single species changes at range boundaries following substantial temperature changes can take from 300 to $2,000 \mathrm{yr}$, and whole community changes require up to 5,000 yr. These rates of change are in no way catastrophic. Further, there is more historical evidence supporting the ability of trees and forests to maintain themselves and grow for centuries and millennia out of equilibrium with climate than evidence showing catastrophic diebacks or rapid changes in community composition that closely track climate. Because climate has always been variable, we should perhaps expect that both species and communities would be able to tolerate moderate and/or short-term changes and therefore would track only long-term changes that were more or less permanent. This damping out of the climate "noise" and tracking of long-term "signal" components of climate change does, in fact, seem to occur. To reformulate growth models to properly reflect this inertia, a more careful consideration of the fundamental niche is necessary. 


\section{DEFINING THE FUNDAMENTAL NICHE}

Factors that should be considered in defining the fundamental niche for model construction include the physiological tolerance of trees to climate extremes, physiological and growth plasticity, and population genetics.

\section{III.A. Tolerance of Climatic Fluctuations}

Most tree species are long lived and, in general, must be able to survive the range of weather conditions experienced during a normal life span. Because tree life spans are commonly longer than $200 \mathrm{yr}$, and often exceed $400 \mathrm{yr}$ (Loehle 1988), trees appear to be able to tolerate a wide range of conditions. The long life spans of trees should result in selection for tolerance to climate variability, with a damping of growth responses to short-term fluctuations. Extreme climate events can result in widespread tree mortality and species decline (e.g., red spruce [Picea rubens] and [sp.] oak decline; Millers et al. 1989). However, this scenario has not been shown to translate into long-term changes in forest composition such as those projected to occur under global warming. Many trees survive these events (as evidenced by living trees sampled for dendrochronological studies), and dead overstory trees are often replaced by conspecific advanced regeneration growing in the more protected microclimate of the understory (Liu and Muller 1993). This circumstance suggests that short-term unusual weather conditions may not cause major changes in forests. Hence, estimates of climatic tolerances of tree species based on average climate at the current geographic range limit may be more restrictive than tolerances estimated from historical weather survived by old trees.

Tree ring data clearly can be used to assess the degree of growth suppression that trees can survive as well as the relationship between climate and tree decline (e.g., LeBlanc and Foster 1992). Such data are not currently available for the majority of species in eastern North America, however. To assess the likely range of climatic fluctuations trees can tolerate, we must turn to other data. Two sources of information present themselves. First, trees of a given age have clearly survived whatever weather occurred during their lifetimes. Second, climatic extremes sufficient to cause diebacks during historical times provide definite evidence of the limits of tolerance. These two types of information are complementary; one provides information on the extremes that at least some trees have tolerated, and the other indicates the specific weather that killed most trees in particular stands.

For living trees, the weather extremes experienced during their lifetimes clearly did not exceed

their tolerance. From this evidence, we cannot infer that all trees of the species survived a particular severe weather event, nor that trees of this species survived on all sites over this period (unless data from many sites are available). Nevertheless, such data give a rough picture of tolerance of extreme and fluctuating conditions. One region that provides a potentially clear picture is the Pacific Northwest. This region has a very high percentage of trees with documented life spans longer than $400 \mathrm{yr}$ (Loehle 1988), and many large areas are dominated by trees more than $500 \mathrm{yr}$ old. These trees germinated before the Little Ice Age began (approx. 550-150 yr ago) and have thus survived an entire cooling and warming cycle over this period, similar in magnitude to GCM climate change projections. Old trees are common on all sites in this region, from moist to dry, lowland to mountain. Thus, survival of the last $500 \mathrm{yr}$ of weather is clearly not anomalous. Weather fluctuations in this coastal region probably were not as severe as in other regions, but an analysis of historical climatic data from the region would be informative.

Long-term climate data from the Southeast have been reconstructed by Stahle and Cleaveland (1992), who used tree ring data from bald cypress (Taxodium distichum) growing in swamps in North Carolina, South Carolina, and Georgia. The authors argued that cypress growth rates are positively related to rainfall because when water levels are high, the water tends to be flowing, and flowing water is relatively oxygenated. The relationship they derived was shown to be quite good at matching historical statewide rainfall records over recent decades. On this basis, they reconstructed spring (March to June) rainfall over the last 1,000 yr (with high values perhaps slightly underestimated). Spring rainfall is a key determinant of growth for trees in this region (e.g., Friend and Hafley 1989; Jacobi and Tainter 1988). Stahle and Cleveland found that spring rainfall values over the period ranged from about 250 to $700 \mathrm{~mm}$, the 10 -yr smoothed values ranged from 325 to $600 \mathrm{~mm}$, and the 30 -yr smoothed values ranged from 375 to $450 \mathrm{~mm}$ (Figure 2). The values fluctuated by this much 
repeatedly over the entire record. For 10 -yr averages, peak-to-trough ratios were 1.85 , while for 30 -yr averages, peak-to-trough ratios were 1.2. Because high rainfall levels were underestimated, the true ranges might be even higher. Several major fluctuations occurred per century (Figure 2), and yearly fluctuations were comparable to those that would occur in going from the Smokey Mountains to lowa. Other examples of significant climatic variation also exist. Scuderi (1993), in a study of highelevation foxtail pine (Pinus balfouriana) in the California Sierra Nevada, found very wide annual variations in temperatures over the last 2,000 yr (Figure 3). In the same region, Graumlich (1993) detected major centennial-scale variations in temperature and decadal-scale fluctuations in precipitation over the last $1,000 \mathrm{yr}$. Pfister $(1981,1984)$ reconstructed temperatures and precipitation for Switzerland from a variety of sources without using tree rings. He found that the 450 -yr range of 5 -yr means of summer temperature was $2.6^{\circ} \mathrm{C}$. The range of 5-yr means for precipitation was $130 \%$ to $65 \%$ of the mean, with a peak-to-trough ratio of 2 . Stocker and Mysak (1992) reviewed a variety of historical data and concluded that regional to global climate fluctuations are significant and common over time scales of decades to centuries.

In all these long-term data sets, the extremely wet, dry, warm, or cold years or runs of years were not anomalous, rare events. Rather, the temperature and precipitation regularly and frequently fluctuated over this range. Over any given 100 -yr period, the temperature and precipitation fluctuated over a range as great as that projected to occur as a result of global warming. Over the life span (several hundred years) of many trees, multiple fluctuations of these magnitudes have certainly been the rule rather than the exception, and thus, we should expect that trees would be able to tolerate such fluctuations. The human tendency to view such fluctuations as extreme is based on our time horizon for viewing these events; our personal experience gives us a perspective on climate on the order of 15$20 \mathrm{yr}$, and we have no concept of intervals of $100 \mathrm{yr}$ or longer. For many trees, by contrast, the fundamental life cycle spans $100 \mathrm{yr}$ and beyond.

One way in which trees tolerate variations in growing conditions such as those documented earlier is by the use of a conservative growth strategy. When the weather is better than average, a tree does not grow at the maximum rate possible. During adverse periods, the tree does not die back entirely, but rather it shortens internodes and produces fewer leaves. In these and other ways, the tree remains in balance with the average climate over a period of several years to decades and avoids becoming overcommitted to a short run of good conditions through too rapid growth, which could lead to death when adverse conditions return. Such conservative strategies are less evident in short-lived, early successional species.

\section{III.B. Plasticity of Response}

One aspect of the tolerance of severe climate conditions by trees that deserves additional consideration is morphological and physiological acclimation responses. Most herbaceous plants have been shown to shift shoot:root ratio in response to growing conditions. The same is likely true of trees, but the data are less extensive. Trees on droughty or nutrient-poor sites are smaller with lower shoot:root ratios that may reduce drought stress and respiratory energy demand (Keyes and Grier 1981; Vogt et al. 1987; LeBlanc unpublished data on several oak species across a moisture gradient in the Midwest). Much of this variation in size and shoot:root ratio develops while the tree is young and actively growing. However, mature trees are generally locked into the biomass partitioning pattern they have constructed, and this restricts the ability of the tree to alter carbon and water demands. Trees that suffer partial dieback in response to climatic stresses (reducing carbon demand and transpiration/leaf area) may be more likely to succumb to complex decline disease (Manion 1991). Many currently existing trees in some parts of North America developed during a period of cooling (1940s to present) and an associated reduction in the frequency and severity of droughts (see LeBlanc [1993] for a review of evidence). Trees that grew under these conditions may have developed large shoot:root ratios that might make them more prone to decline and mortality if climate change results in increased frequency and severity of droughts. However, if severe climate conditions persist, trees that die may well be replaced by individuals of the same species that will develop a more conservative body organization (lower shoot:root ratios) that is better able to tolerate drier conditions. Hence, in spite of forest dieback after a series of severe droughts, regeneration may be comprised of the same species as the dead trees (i.e., No change in forest composition). Species replacement would only 
occur if species better adapted to the new climate conditions were present in the regeneration pool and outcompeted species with inferior climatic tolerances. However, even if species composition does not change rapidly, decreasing shoot:root ratios could very well result in a decrease in aboveground productivity of forests, which would have many ramifications for ecosystem function and would be of considerable interest to the forest products industry.

\section{III.C. Genetics}

A shortcoming of the climate-response functions in forest simulation models is that they are necessarily presumed to be spatially and temporally constant; climate-response functions for a species are not allowed to evolve through natural selection. There is widespread evidence of genetic variability in the physiological responses to temperature and/or moisture stress of tree species, including sugar maple (Kriebel 1957), sitka spruce (Picea sitchensis) (Campbell et al. 1989), loblolly pine (Pinus taeda) (Bongarten and Teskey 1986; Harrington 1991), Douglas. fir (Pseudotsuga menziesii) (Irgens-Moller 1957), and western hemlock (Tsuga heterophylla) (Kuser and Ching 1980).

A common garden provenance study of sugar maple by Kriebel (1957) found substantial differences among provenances in the response of this species to summer drought, early/late growing season freeze, and minimum winter temperature. This study found that the percentage of crown affected by sun scorch resulting from summer drought conditions was significantly negatively correlated with the average July temperature of the seed source. Sun scorch injury increased along provenance gradients from south to north and from west to east. Also, the survival rate of seedlings after the drought was positively correlated with the maximum summer temperature of the seed source. Cold injury due to late spring or fall frosts was more severe for southern provenances of sugar maple than for central and northern provenances. Kriebel (1957) concluded that the "northern" ecotype ( $A$. saccharum) was quite sensitive to drought and high temperature, but that the "central" ecotypes ( $A$. saccharum and $A$. nigrum) found in the Midwest had high resistance to drought and leaf scorch, as well as high resistance to winter injury. Hence, the ecotype of sugar maple at the southern/western range limit is that which should best be able to tolerate global warming and associated increases in drought frequency.

Morphologically and ecologically distinct ecotypes have also been described for eastern hemlock (Kessel 1979). One ecotype occurs on subxeric sites and is temperature limited; the other occurs on mesic sites and is generally precipitation limited. Intermediate ecotypes are also found. The ratio of the two major ecotypes within populations varies throughout the range of the species; this variation may influence range limits.

While the studies described earlier documented physiological differences between geographically separated provenances or "ecotypes," other studies have demonstrated variation in physiological responses between populations of the same tree species growing in different habitats within a particular region. Ledig and Kerbobo (1983) demonstrated ecotypic differences in the temperature-response curve for photosynthesis between sugar maple populations along a single altitudinal gradient, where between-population gene flow was possible. Kubiske and Abrams (1992) demonstrated ecotypic differences in physiological and morphological responses to drought between adjacent populations of northern red oak (Quercus rubra) growing on xeric and mesic sites. These studies suggest that tree species can adjust to fine-scale variation in climatic conditions through adaptation and acclimation. Hamrick (1979) determined that long-lived woody perennial plants (trees) have high levels of genetic variation (as measured by allozyme analysis). High levels of genetic variability were found both within populations and between populations.

Hamrick et al. (1979) concluded that plants can respond to temporal or spatial environmental change either through individual developmental plasticity or through the evolution of locally adapted ecotypes or provenances. Hence, it is possible that tree species may respond to climatic change not only through morphological or physiological acclimation, but also through differential reproduction and survival, which increases the representation of genotypes better able to deal with a warmer and or drier climate. Contemporary examples of such changes in the genetic composition of tree populations have been documented for white pine (Pinus strobus) and poplar (sp.) populations stressed by high ozone concentrations (Mann et al. 1980; Berrang et al. 1991). It is not clear how much genetic change could result from such selection over the 100- to 200-yr period over which climate may change. 
The research described above is only a small part of a much larger literature that demonstrates the wide genetic and phenotypic variability of plant physiological and morphological responses to climatic stresses. The fact that tree species include physiological ecotypes, each with distinct limits of tolerance responses to changes in temperature and moisture availability, argues against the use of simple, parabolic climate-response functions. The range limits of a species encompass multiple ecotype ranges. Any geographically defined estimation of species climate-response curves aggregates ecotype-response curves, each with a distinct optimum. Hence, there is some reason to expect that species-level climate-response curves should have a broader optimum region and perhaps more gradual decreases in physiological function as conditions deviate from optimum. At least one study of the ecophysiology of a specific tree species (black spruce) has demonstrated a temperature-response curve that has this shape (Bonan and Sirois 1992).

\section{III.D. Implications}

The limitations in the climate-response functions of forest simulation models (confounding of realized and fundamental niche, failure to consider tree tolerance and acclimation responses to climatic variability, failure to consider spatial and temporal change in response functions due to natural selection, and unrealistic dispersal functions) all lead to overestimation of forest sensitivity to climate change. Current models project growth decline and widespread tree mortality as a result of warming, whereas a longer, less traumatic process of competitive displacement may be more likely. These limitations do not affect the ability of existing models to predict current equilibrium relationships between forests and climate or long-term outcomes of vegetation response to climate change (with exceptions as noted). However, these limitations are cause for questioning the validity of projections of forest responses during the near-future, transient period of climate change. These considerations lead to a reformulation of stand models.

\section{III.E. Climate-Disturbance Interactions}

While the limitations of model climate-response functions described earlier likely result in overestimation of forest sensitivity to climate change, the omission of climate-disturbance interactions from forest simulation models will certainly lead to underestimation of forest sensitivity. There is significant evidence in the literature of a relationship between climate and the frequency and magnitude of forest fires (e.g., Clark 1990; Flannigan and Van Wagner 1991; Swetnam 1993), and of forest decline due to outbreaks of forest pests and pathogens (e.g., Christiansen et al. 1987; Houston 1987; Mattson and Haack 1987; Millers et al. 1989; Swetnam and Lynch 1993). In addition, a warmer climate may result in extensions of northern range limits for some pest species currently limited by winter extremes. Because insects are cold-blooded, a warmer climate would also increase individual and population growth rates, as well as survival of forest pests, increasing the potential for destructive outbreaks. This combination of range expansions and increased potential for outbreaks could result in more frequent and widespread forest decline (see Gates [1993] for a review). If global warming results in more frequent and severe droughts, the interaction of direct climate effects and droughtinsect interactions could easily cause frequent and widespread forest decline and tree mortality (e.g., LeBlanc and Foster 1992). Hence, projections of increased levels of disturbance, forest decline, and mortality in response to warming are not unreasonable according to the current understanding of the role of climate stresses (e.g., drought and freeze events) in the decline process of many tree species. The exact distribution and extent of such forest decline is an unanswered question because they will depend on many factors operating at the local site, species, and regional levels. Whether increased disturbance frequency associated with a warmer climate will result in rapid replacement of tree species or loss of forest cover is unknown. Assuming the limitations to species migration described earlier, and human fire suppression in areas of forest dieback, natural regeneration processes may well replace dead forests with new ones of similar species composition. 


\section{MODELING FOREST RESPONSE TO CLIMATE CHANGE BY USING THE FUNDAMENTAL NICHE}

As described earlier, several aspects of model function are deficient in representing the fundamental niche and physiological tolerance. From our analysis, we do not believe that response surface or biogeographic correlation approaches are capable of predicting the transient responses of forests, even if they could be modified to more closely capture the fundamental niche. Therefore, we focus on gap-phase stand models. We propose that the following gap model functions need reformulation to capture the fundamental niche: dispersal, the temperature and moisture growth response functions, competition, the mortality function, and climate-disturbance interactions. A more accurate database to determine life spans (e.g., Loehle 1988) should also be used.

\section{IV.A. Reproduction and Dispersal}

In typical stand simulations (e.g., Solomon 1986), dispersal is assumed to be universal. That is, all species in the model (e.g., all species from eastern North America) are available for germination in every gap. This approach gives realistic results when the equilibrium response and responses to small perturbations are being modeled. For the study of transients, however, it is not valid (Pacala and Hurtt 1993) because over a period of a few hundred years, invading (i.e., more southern) species may not have time to migrate into the region. When it is assumed that all species have instant access to all sites, the rate of species transition in response to climate change increases to an unrealistic pace. We argue that the species pool at a given simulated site should include only species currently found near the site, plus those known to be rapid dispersers. This definition will resolve the effects of limited dispersal. Further, seed rain should be made proportionate to current species abundance (properly weighted for seed output) to represent properly the invasion ability of initially rare southern species, as in the Sortie model (Pacala et al. 1993). Some of the ideas of Fulton (1993) are appropriate for handling seedling responses.

Another factor that should be included is stump and root sprouting. Stump sprouting enables oak saplings to persist in the understory even when the shade is too heavy for seedling survival. American chestnut has persisted by sprouts for decades in spite of failure to reproduce. Stump and root sprouts thus act to increase stand inertia in the face of changing climates.

\section{IV.B. Growth-Response Functions}

Growth functions must be reconceptualized before forest response during the transient period can be modeled properly. The critical model functions responsible for diebacks under simulated $\mathrm{CO}_{2-}$ doubling climates are temperature response and moisture response. We argue that the proper temperature-response function curve is wider and broader than the ones used in previous studies (Figure 4). Studies have shown that in the central part of their ranges, species are quite insensitive to temperature as measured by growth response (e.g., Brubaker 1986), except during droughts because under these conditions, a tree usually becomes limited by water or nutrients well before the growing season is completed. We propose a revised temperature-response function that reflects this fact. We argued earlier that trees can grow over a wider range of temperatures than is reflected in their geographic range. Our growth function models this response (Figure 4) by being broader than the standard parabolic function used in the past. This growth function is tentative at this time and needs testing against field data. A similar reexamination of the moisture-response function is also needed. Ideally, a joint temperature-moisture (evapotranspiration) response function is needed. An extensive literature describes plantings of trees outside their normal ranges in forest plantations, provenance tests, Christmas tree plantings, botanical gardens, and urban plantings (e.g., Wright 1976). This literature can be used to establish the geographic range corresponding to the fundamental niche and thus to calibrate the growth curves for temperature and moisture for the model species.

Another valuable source of information for improving and/or validating climate-response functions in forest simulation models is tree-ring-based, dendroclimatic analysis that relates historical fluctuations in tree growth to climate. Shugart (1984) and Graumlich (1989) also recognized this relatively unexplored opportunity for making climate-response functions in forest simulation models more realistic. Dendroclimatic analyses could make three distinct contributions by serving to (1) 
validate the climate-response functions of forest simulation models (e.g., Foster and LeBlanc 1993), (2) improve existing growth and climate-response functions, and (3) identify significant growthclimate relationships not presently included in forest simulation models. If climate-response functions in forest simulation models are valid, the growth indices produced by these functions should be significantly correlated with actual tree growth responses to climate. At the very least, the nature of the growth-climate relationship stipulated by the model function should be consistent with observed growth-climate associations.

As demonstrated by Cook and Cole (1991), dendroclimatic analyses can be used to test hypotheses regarding the nature of growth-climate relationships for specific tree species. In this regard, the climate-response functions currently used in forest simulation models are really hypotheses to be tested, not established fact. For example, we can state one hypothesis given by such a such model as follows: if tree growth, survival, and distribution are limited by high temperature at the southern range limit, then radial growth should be negatively correlated with temperature variables. Many dendroclimatic studies have shown that tree growth responses to changes in temperature vary from positive to negative, depending on the time of year. Recent dendroclimatology studies are increasingly based on tree physiology (e.g., Foster and LeBlanc 1993; Fritts et al. 1991).

A difficulty in basing models on dendroclimatic analysis is the paucity of extant data and the expense of collecting it (Graumlich 1989). However, it may not be necessary to obtain tree ring data for every species and ecotype in order to use this approach. Efforts could be focused on some of the major species, particularly to see whether their ranges appear to be, in fact, limited by climatic variables. Available data, such as confinement to microsites at range boundaries (e.g., only found on north slopes at the southern range limit), could supplement these analyses. If ranges do not appear to match limits defined by growing degree-days, then dendroclimatic analyses could be used to help determine which climatic variables are in fact limiting.

Because $\mathrm{CO}_{2}$ affects water use and potentially drought stress, $\mathrm{CO}_{2}$ effects must be included. While few past modeling studies have included $\mathrm{CO}_{2}$, several new studies (e.g., the Sortie model of Pacala et al. [1993]) are beginning to do so.

\section{IV.C. Competition}

Because the net growth of a tree depends on both its basic response to climate and the degree of competition, competition must be included in a model based on the fundamental niche. Competition for light is a key factor. The Sortie model (Pacala et al. 1993) provides a particularly sophisticated analysis of light regimes, using tree crown size and opacity together with incident light angles over diurnal and seasonal periods to calculate how much light each tree receives. Such an approach is essential. Influence of soil, water, and nutrients is another key aspect of competition that has been included in only a few growth models. Inclusion of these factors allows the temperaturedrought interaction to be made explicit via water limitation, allows different microsites to be distinguished, and makes competition explicit via differential ability to extract water from soil. A promising approach to explicit representation of spatial aspects of competition between neighboring trees is ecological field theory (Sharpe et al. 1986).

\section{IV.D. Mortality Function}

The final major model modification we propose concerns the mortality function. This is the key function in predicting major diebacks following warming. In extant simulations, a constant probability of mortality is modeled on the basis of the life span, giving a negative exponential survival curve. Poor growing conditions that retard growth lead to an increased mortality rate for individual trees. This function is generally constant across all species or is proportional to life span and has been estimated by rule of thumb (limitation noted by Gates [1993] and Pacala and Hurtt [1993]). Several problems result from this formulation. First, it does not recognize that tree species differ greatly in their abilities to tolerate poor growing conditions and to grow slowly (e.g., Figure 5). In general, longlived species and those adapted to extreme sites will have a greater tolerance for slow growth without ensuing death (Loehle 1988). Second, slow growth due to shading suppression may have very little effect on mortality for certain species that can tolerate shade, such as eastern hemlock. Third, adult dominant trees may be able to tolerate slow growth due to adverse weather for several to many years, 
whereas a crowded tree of the same species might succumb. Finally, life span is a crucial parameter that has been given insufficient attention. We discussed these factors earlier; next, we reformulate the mortality function to reflect these considerations. In particular, our mortality response function takes into account not just the current growth rate but the length of time that low growth has prevailed.

An improved mortality function would take into account the above-mentioned factors, which lead to differences between species in tolerance of low growth rates and the manner in which the probability of mortality increases as growth is progressively reduced (Figure 5). A typical equation that gives this relation is as follows:

$$
\mathrm{M}=\mathrm{ae}^{-\mathrm{bg}} \text {, }
$$

where $M$ is mortality rate, $a$ is the intercept, $g$ is the growth rate, and $b$ is the effect of increased growth rate in reducing mortality. Parameter $a$ is bounded between 0 and 1 .

When such a mortality function is fitted from growth data, the growth rate immediately prior to death is typically noted for trees that have recently died. Examination of the entire record of a tree's growth, however, often reveals that the tree survived many brief periods of very low growth during its life. During brief periods of adverse weather, trees may grow very slowly and even suffer some damage, but they can usually recover. During prolonged periods of adverse (particularly moisture deficit) conditions, damage to the tree accumulates as branch tips die and root mass decreases. Many years of slow growth usually precede death, and the mortality probability increases as more years of slow growth pass. Thus, the mortality function is not actually stationary (dependent only on the current growth rate), but rather it is influenced by the length of growth suppression. In a complete model of tree health that considered such factors as root mass, leaf area, and starch reserves, mortality could be related to the current state of the system. However, in a simple forest growth model, the growth rate variable alone provides insufficient information to relate the current growth rate unambiguously to the condition of the tree and thus to mortality.

In our proposed model, we instead use a modified mortality function that takes into account the length and severity of prior growth suppression. We begin with Equation 1 but with a modified intercept:

$$
M=c e^{-b g} \text {, }
$$

where $c$ is the constant for the risk due to the current year's low growth rate (where all immediately prior years were nonstressful), and $c<a$ ( $a$ from Equation 1).

The intercept $c$ increases as a function of the degree of growth suppression in prior years:

$$
\mathrm{c}=\mathrm{f}[\mathrm{MA}(\mathrm{g})]
$$

where $M A(g)$ is the moving-average growth rate over the previous 5-10 yr, as appropriate for the species. The function $f$ can be determined from data like those of LeBlanc and Foster (1992).

The formulation in Equation 3 shifts the mortality curve up as the average of the previous period's growth decreases, as in Figure 6 (illustrating an arbitrary number of prior years of suppression). Equation 3 is a tentative model that demonstrates one approach to this problem. Note that the base curve for 1 yr of stress (Figure 6) is much lower than that which would be estimated from ring width correlations with death, because at death, a tree has usually had a low growth rate for many years. The mortality function (Equation 3) incorporates tolerance of short-term stresses. For trees intolerant of stress, the base curve for 1 yr of growth suppression will be similar to that estimated from ring width at time of death. The moving-average period will be longer for trees that can tolerate longer periods of adverse conditions.

The function in Equation 3 is added to base mortality to obtain total mortality. Base mortality is due not to growth suppression but to random causes unrelated to growth rate (e.g., storms). This modeling provides a basis for fitting the mortality-response function parameters in Equations 2 and 3. Maximum likelihood methods can be used for initial estimation of the model from field data on mortality. We may improve the model and test it as follows:

- The model is run for a nominal climate over several hundred years with a large number of simulated plots of all ages.

- Simulated age-frequency distributions are compared with those expected for a negative exponential survivorship for a species with the given life span. 
- The parameters of Equations 2 and 3 are iteratively modified so that the proper survivorship curve is more closely approximated. In this formulation, mortality will be relatively episodic and concentrated during runs of adverse weather, as is actually observed.

This model prevents exaggerated mortality resulting from short-term extreme events and specifically incorporates differences between species in tolerance of climatic fluctuations related to life span, tolerance of drought, and tolerance of suppression. During simulations of altered weather (warming), this model formulation should give more realistic mortality responses than current models.

The revised model can be tested to see whether it can replicate actual forest composition in a variety of regions for normal weather conditions. The ability to replicate successional sequences and age and size distributions should also be tested. For nominal (equilibrium) weather conditions, the revised and original models are expected to give very similar results. The results should differ in major ways only for transient conditions. Transient dynamics can be tested in several ways. It is now known that periodic, severe, multiyear droughts are a recurring feature in the Southeast (Stahle and Cleaveland 1992). Models run under these fluctuating conditions should give a long-term forest composition similar to that observed. In addition, local temperature anomalies of $2.2^{\circ} \mathrm{C}$ (century-scale warming trend) in central New England and of about $2^{\circ} \mathrm{C}$ during the dust bowl drought of the $1930 \mathrm{~s}$ in the Great Plains can be used to compare historical forest responses with those predicted from extant models and from our new model. Diebacks observed on special edaphic sites such as shallow soils can also be used for calibration.

\section{IV.E. Modeling Disturbance Regimes}

Mortality functions of existing forest simulation models include a stochastic mortality component that is meant to simulate probabilistic mortality associated with factors extrinsic to tree and stand development (i.e., disturbance). We believe there is sufficient information available in the literature for a more explicit modeling of disturbance-induced mortality, particularly for fire and insect outbreaks. Bonan et al. (1990) included effects of warmer, drier climatic conditions on fire regime in their model-based analysis of climate change effects on boreal forests. Their analysis indicated that increased fire frequency could play a significant role in boreal forest responses to a warmer climate. Studies of some forest pests also indicate a linkage between climatic conditions and insect or pathogen outbreaks (e.g., Swetnam and Lynch 1993). Empirical relations between climate and insect or pathogen outbreaks could be used to formulate algorithms that reflect the interactions of changing climatic conditions and altered frequency, severity, and/or magnitude of pest outbreaks. These algorithms could then be translated into species-specific probabilities of mortality as a function of tree susceptibility to pests or fire. Swetnam's (1993) analysis of the linkages between weather cycles and fire regimes is an example of this linkage for fire. Similar functions could be determined for frequency of severe storms. Methods exist for extrapolating the distribution of extreme events under a changing climate (Gaines and Denny 1993). The role of disturbance in altering successional patterns and in altering species turnover rates is crucial for properly projecting the effects of a changing climate.

\section{IV.F. Consequences of Proposed Modifications}

The net effect of the modifications to stand growth models we propose is to increase the tolerance of trees to variable climate and to increase the inertia of established stands in those models. Realistic seed dispersal functions slow down migration rates of species that might displace species already present on a site. Making seed production a function of existing species composition gives an advantage to species that are currently abundant. More realistic mortality functions increase the tolerance of trees to climate variability. Representation of the fundamental niche prevents trees from dying under climates they can actually tolerate, thus making model response more realistic. Overall, models constructed in this direction should exhibit increased inertia compared with extant models. However, this vegetation inertia could be counterbalanced if disturbance frequency and intensity increase. 


\section{CONCLUSION: NET EFFECTS OF CLIMATE CHANGE}

On the basis of foregoing analysis, we believe it is possible to draw some general conclusions about the consequences of projected climatic change for forest ecosystems. However, to draw more detailed conclusions, extant models must be modified to more accurately reflect the physiological and ecological mechanisms of forest response to climate, as suggested herein, and specific scenarios simulated for different regions. Two key issues remain unresolved: the likely rates of vegetation change following warming and the possible effects of changes in disturbance regimes.

We believe the rates of change following climatic warming will likely be much slower than the rates projected from extant models. Analysis of historical records of similar warmings suggests that periods of several hundred to several thousand years are required for significant change in vegetation. Records of catastrophic vegetation change following climate change have not yet been identified. This vegetation inertia is consonant with the direction of changes in model output we would expect if the deficiencies we have noted were to be corrected as we have suggested. This is not to say that no change will occur, but the catastrophic scenarios generated by some models may be overly alarmist.

However, to the extent that climate change increases the frequency, severity, or magnitude of disturbances, substantial destruction or alteration of forest ecosystems may well occur. For those types of disturbances that are currently managed by humanity, additional resources may well be required to control such disturbances under a warmer climate regime, and it may not be possible to extend this control to noncommercial forest lands. Hence, increases in climate-related disturbance could result in increased management costs on commercial forest lands, as well as degradation of other forest values (e.g., aesthetic, wildlife habitat, recreation) on noncommercial lands, including national parks and designated wilderness areas.

\section{ACKNOWLEDGMENTS}

This research was supported in part by the National Council for Air and Stream Improvement (NCASI). The views expressed herein do not necessarily reflect those of NCASI. Partial support was also provided in connection with work performed under contract W-31-109-ENG-38 with the U.S. Department of Energy, Office of Energy Research, Office of Health and Environmental Research, Program for Ecosystem Research. Helpful reviews were provided by Eric Vance and Robert Jones.

\section{LITERATURE CITED}

Beerling, D.J., and F.I. Woodward. 1993. Ecophysiological responses of plants to global environmental change since the last Glacial Maximum. New Phytol. 125:641-648.

Berrang, P., D.F. Karnosky, and J.P. Bennett. 1991. Natural selection for ozone tolerance in Populus tremuloides: An evaluation of nationwide trends. Canadian J. Forest Research 21: 1091-1097.

Bonan, G.B., H.H. Shugart, and D.L. Urban. 1990. The sensitivity of some high-latitude boreal forests to climatic parameters. Climatic Change 16:9-29.

Bonan, G.B., and L. Sirois. 1992. Air temperature, tree growth, and the northern and southern range limits of Picea mariana. J. Vegetation Science 3:495-506.

Bongarten, B.C., and R.O. Teskey. 1986. Water relations of loblolly pine seedlings from diverse geographic origins. Tree Physiology 1:265-276.

Botkin, D.B. 1972. Some ecological consequences of a computer model of forest growth. J. Ecology 60:849-872. 
Botkin, D.B., and R.A. Nisbet. 1992. Forest response to climatic change: Effects of parameter estimation and choice of weather patterns on the reliability of projections. Climatic Change 20:87-111.

Botkin, D.B., R.A. Nisbet, and T.E. Reynolds. 1989. Effects of climate change on forests of the Great Lakes states. pp. 2-1 to 2-31 in: J.B. Smith and D. Tirpak (eds.), The Potential Effects of Global Climate Change on the United States. U.S. EPA, Washington, D.C.

Brubaker, L.B. 1986. Responses of tree populations to climatic change. Vegetatio 67:119-130.

Campbell, I.D., and J.H. McAndrews. 1993. Forest disequilibrium caused by rapid Little Ice Age cooling. Nature 366:336-338.

Campbell, R.K., W.A. Pawuk, and A.S. Harris. 1989. Microgeographic genetic variation of Sitka spruce in southeastern Alaska. Canadian J. Forest Research 19:1004-1013.

Cannell, M.G.R. 1987. Climatic warming and spring phenology of trees. pp. 283-296. In: D.P. Lavender. Woody plant growth in a changing chemical and physical environment. Proceedings of the workshop of IUFRO Working Party on Shoot Growth Physiology, Vancouver, B.C., Canada, July 1987.

Christiansen, E., R.H. Waring and A.A. Berryman. 1987. Resistance of conifers to bark beetle attack: Searching for general relationships. Forest Ecology and Management 22:89-106.

Clark, J.S. 1990. Fire and climate change during the last $750 \mathrm{yr}$ in northwestern Minnesota. Ecological Monographs 60: 135-159.

Cole, K. 1985. Past rates of change, species richness, and a model of vegetational inertia in the Grand Canyon, Arizona. American Naturalist 125:289-303.

Cook, E.R., and J. Cole. 1990. On predicting the response of forests in eastern North America to future climate change. Climatic Change 19:271-282.

Coope, G.R. 1977. Fossil coleopteran assemblages as sensitive indicators of climatic changes during the Devensian (Last) cold stage. Philosophical Trans. Royal Soc. Lond. B. 280:313-340.

Cox, C.B., and P.D. Moore. 1980. Biogeography. John Wiley \& Sons, New York.

Cwynar, L.C., and R.W. Spear. 1991. Reversion of forest to tundra in the central Yukon. Ecology 72:202-212.

Dale, V.H., and J.F. Franklin. 1989. Potential effects of climate change on stand development in the Pacific Northwest. Canadian J. Forest Research 19:1581-1590.

Davis, M.B. 1981. Quaternary history and the stability of forest communities. In: D.C. West, H.H. Shugart, and D.B. Botkin (eds.). Forest Succession: Concepts and Applications. Springer-Verlag, New York.

Davis, M.B. 1989. Lags in vegetation response to greenhouse warming. Climatic Change 15:75-82.

Davis, M.B., and D.B. Botkin. 1985. Sensitivity of cool-temperate forests and their fossil pollen record to rapid temperature change. Quaternary Research 23:327-340. 
Davis, M.B., K.D. Woods, S.L. Webb, and R.P. Futyma. 1986. Dispersal versus climate: Expansion of Fagus and Tsuga into the upper Great Lakes region. Vegetatio 67:93-103.

Denton, S.R., and B.V. Barnes. 1987. Tree species distributions related to climatic patterns in Michigan. Canadian J. Forest Research 17: 613-629

Ellenberg, H. 1988. Vegetation Ecology of Central Europe. Cambridge University Press, Cambridge, England.

Emanuel, W.R., H.H. Shugart, and M.P. Stevenson. 1985. Climatic change and the broad-scale distribution of terrestrial ecosystem complexes. Climatic Change 7:29-43.

Flannigan, M.D., and C.E. Van Wagner. 1991. Climate change and wildfire in Canada. Canadian J. Forest Research 21: 66-72.

Foster, J.R., and D.C. LeBlanc. 1993. A physiological approach to dendroclimatic modeling of oak radial growth in the midwestern United States. Canadian J. Forest Research 23: 783-798.

Fowells, H.A. 1965. Silvics of Forest Trees of the United States. Agriculture Handbook 271. USDA Forest Service, Washington, D.C.

Friend, A.L., and W.L. Hafley. 1989. Climatic limitations to growth in loblolly and shortleaf pine (Pinus taeda and $P$. echinata): A dendroclimatological approach. Forest Ecology Management 26:113-122.

Friend, A.L., and H.H. Shugart. 1993. A physiology-based gap model of forest dynamics. Ecology 74: 792-797.

Fritts, H.C., E.A. Vaganov, I.V. Sviderskaya, and A.V. Shashkin. 1991. Climatic variation and treering structure in conifers: Empirical and mechanistic models of tree-ring width, number of cells, cell size, cell-wall thickness, and wood density. Climate Research 1:97-116.

Fulton, M.R. 1993. Rapid simulations of vegetation stand dynamics with mixed life-forms. pp. 251-271. In: A.M. Solomon and H.H. Shugart (eds.) Vegetation Dynamics and Global Change. Chapman and Hall, New York.

Gaines, S.D., and M.W. Denny. 1993. The largest, smallest, highest, lowest, longest, and shortest: Extremes in ecology. Ecology 74:1677-1692.

Gates, D.M. 1990. Climate change and forests. Tree Physiology 7:1-5.

Gates, D.M. 1993. Climate Change and its Biological Consequences. Sinauer Associates, Sunderland, Mass.

Gear, A.J., and B. Huntley. 1991. Rapid changes in the range limits of Scots pine 4000 years ago. Science 251:544-547.

Graumlich, L.J. 1989. The utility of long-term records of tree growth for improving stand simulation models. pp. 39-49. in G.P. Malanson (ed.). Natural Areas Facing Climate Change. SPB Academic Publ., the Hague, the Netherlands.

Graumlich, L.J. 1993. A 1,000-year record of temperature and precipitation in the Sierra Nevada. Quaternary Research 39:249-255. 
Guetter, P.J., and J.E. Kutzbach. 1990. A modified Koppen classification applied to model simulations of glacial and interglacial climates. Climatic Change 16:193-215.

Guilding, L. 1825. An Account of the Botanic Garden in the Island of St. Vincent. R. Griffin \& Co., Glasgow, Scotland.

Hamburg, S.P., and C.V. Cogbill. 1988. Historical decline of red spruce populations and climatic warming. Nature 331:428-431.

Hamrick, J.L. 1979. Genetic variation and longevity. pp. 84-107. in O.T. Solbrig, S. Jain, G.B. Johnson, and P.H. Raven (eds.). Topics in Plant Population Biology. Columbia University Press, New York.

Hamrick, J.L., Y.B. Linhart, and J.B. Mitton. 1979. Relationship between life history characteristics and electrophoretically detectable genetic variation in plants. Annual Review of Ecology and Systematics 10:173-200.

Harrington, C.A. 1991. Retrospective shoot growth analysis for three seed sources of loblolly pine. Canadian J. Forest Research 21: 306-317.

Hodges, D.G., F.W. Cubbage, and J.L. Regens. 1992. Regional forest migrations and potential economic effects. Environmental Toxicology and Chemistry 11:1129-1136.

Houston, D.R. 1987. Forest tree declines of past and present: Current understandings. Canadian J. Plant Pathology 9: 349-360.

Irgens-Moller, H. 1957. Ecotypic response to temperature and photoperiod in Douglas-fir. Forest Science 3:79-83

Jacobi, J.C., and F.H. Tainter. 1988. Dendroclimatic examination of white oak along an environmental gradient in the Piedmont of South Carolina. Castanea 53:252-262.

Kauppi, P., and M. Posch. 1985. Sensitivity of boreal forests to possible climatic warming. Climatic Change 7:45-54.

Kavanagh, K., and M. Kellman. 1986. Performance of Tsuga Canadensis at the center and northern edge of its range - a comparison. J. Biogeography 13:145-157.

Kessel, S.R. 1979. Adaptation and dimorphism in eastern hemlock, Tsuga Canadensis (L.) Carr. American Naturalist 113:333-350.

Keyes, M.R., and C.C. Grier. 1981. Above- and belowground net production in 40-year-old Douglasfir stands on low and high productivity sites. Canadian J. Forest Research 11: 599-605.

Kriebel, H.B. 1957. Patterns of Genetic Variation in Sugar Maple. Research Bulletin 791. Ohio Agriculture Experiment Station, Wooster, $\mathrm{OH}$.

Kubiske, M.E., and M.D. Abrams. 1992. Photosynthesis, water relations, and leaf morphology of xeric versus mesic Quercus rubra ecotypes in central Pennsylvania in relation to moisture stress. Canadian J. Forest Research 22: 1402-1407.

Kullman, L., and O. Engelmark. 1991. Historical biogeography of Picea abies (L.) Karst. at its subarctic limit in northern Sweden. J. Biogeography 18:63-70. 
Kuser, J.E., and K.K. Ching. 1980. Provenance variation in phenology and cold hardiness of western hemlock seedlings. Forest Science 26: 463-470.

LeBlanc, D.C. 1993. Spatial and temporal variation of oak growth-climate relationships along a pollution gradient in the midwestern United States. Canadian J. Forest Research 23: 772-782.

LeBlanc, D.C., and J.R. Foster. 1992. Predicting effects of global warming on growth and mortality of upland oak species in the midwestern United States: A physiologically based dendroecological approach. Canadian J. Forest Research 22:1739-1752.

Ledig, F.T., and D.R. Kerbobo. 1983. Adaptation of sugar maple populations along altitudinal gradients: Photosynthesis, respiration, and specific leaf weight. American J. Botany 70:256-265.

Lenihan, J.M. 1993. Ecological response surfaces for North American boreal tree species and their use in forest classification. J. Vegetation Science 4:667-680.

Liu, Y., and R.N. Muller. 1993. Effect of drought and frost on radial growth of overstory and understory stems in a deciduous forest. American Midland Naturalist 129:19-25.

Loehle, C. 1987. Errors of construction, evaluation, and inference: A classification of sources of error in ecological models. Ecological Modelling 36:297-314.

Loehle, C. 1988. Tree life history strategies: The role of defenses. Canadian J. Forest Research $18: 209-222$.

Malanson, G.P. 1993. Comment on modeling ecological response to climatic change. Climatic Change 23:95-109.

Malanson, G.P., W.E. Westman, and Y.-L. Yan. 1992. Realized versus fundamental niche functions in a model of chaparral response to climatic change. Ecological Modeling 64:261-277.

Manion, P.D. 1991. Tree Disease Concepts 2nd Ed. Prentice Hall, Englewood Cliffs, N.J.

Mann, L.K., S.B. McLaughlin, and D.S. Shriner. 1980. Seasonal physiological responses of white pine under chronic air pollution stress. Environmental Experimental Botany 20:99-105.

Mattson, W.J., and R.A. Haack. 1987. The role of drought in outbreaks of plant-eating insects. Bioscience 37: 110-118.

Mercer, J.H. 1972. The lower boundary of the Holocene. Quaternary Research 2:15-24.

Millers, I., D.S. Shriner, and D. Rizzo. 1989. History of hardwood decline in the eastern United States. General Technical Report NE-126. USDA Forest Service, Northeastern Experiment Station, Raynor, Penn.

Mitchell, J.F.B. 1983. The seasonal response of a general circulation model to changes in $\mathrm{CO}_{2}$ and sea temperatures. Quarterly J. Royal Meteorological Society 109:113-152.

Mitchell, J.F.B., and G. Lupton. 1984. A $4 \times \mathrm{CO}_{2}$ integration with prescribed changes in sea surface temperatures. Progress Biometeorology 3:353-374.

Monserud, R.A., N.M. Tchebakova, and R. Leemans. 1993. Global vegetation change predicted by the modified Budyko model. Climatic Change 25:59-83. 
Mueller-Dombois, D. 1986. Perspectives for an etiology of stand-level dieback. Annual Review Ecology and Systematics 17:221-243.

Nikolov, N.T., and D.G. Fox. 1994. A coupled carbon-water-energy-vegetation model to assess responses of temperate forest ecosystems to changes in climate and atmospheric $\mathrm{CO}_{2}$. Part I. Model concept. Environmental Pollution 83: 251-262.

Overpeck, J.T., and P.J. Bartlein. 1989. Assessing the response of vegetation to future climate change: Ecological response surfaces and paleoecological model validation. pp. 1-1 to 1-31. in The Potential Effects of Global Climate Change on the United States. Appendix D, Forests. U.S. Environmental Protection Agency, Washington, D.C.

Overpeck, J.T., P.J. Bartlein, and T. Webb. 1991. Potential magnitude of future vegetation change in Eastern North America: Comparisons with the past. Science 254:692-695.

Pacala, S.W., and G.C. Hurtt. 1993. Terrestrial vegetation and climate change: Integrating models and experiments. pp. 57-73. in P.M. Kareiva, J.G. Kingsolver, and R.B. Huey (eds.). Biotic Interactions and Global Change. Sinauer Associates, Sunderland, Mass.

Pacala, S.W., C.D. Canham, and J.A. Silander, Jr. 1993. Forest models defined by field measurements. I. The design of a northeastern forest simulator. Canadian J. Forest Research 23:1980-1988.

Pastor, J., and W.M. Post. 1988. Response of northern forests to $\mathrm{CO}_{2}$ induced climate change. Nature 334:55-58.

Perry, D.A., J.G. Borchers, S.L. Borchers, and M.P. Amaranthus. 1990. Species migrations and ecosystem stability during climate change: The belowground connection. Conservation Biology 4:266-274.

Peters, R.L. 1990. Effects of global warming on forests. Forest Ecology and Management 35:13-33.

Pfister, C. 1981. An analysis of the Little Ice Age climate in Switzerland and its consequences for agricultural production. pp. 214-248. in T.M.L. Wigley (ed.). Climate and History. Cambridge University Press, Cambridge, England.

Pfister, C. 1984. The potential of documentary data for the reconstruction of past climates: Early 16th to 19 th century Switzerland as a case study. pp. 331-337. in N.A. Morner and W. Karlen (eds.). Climatic Changes on a Yearly to Millennial Basis. D. Reidel Publishing Company.

Pigott, C.D. 1981. Nature of seed sterility and natural regeneration of Tilia cordata near its northern limit in Finland. Ann. Bot. Fennici 18:255-263.

Pigott, C.D., and J.P. Huntley. 1981. Factors controlling the distribution of Tilia cordata at the northern limits of its geographical range. III. Nature and causes of seed sterility. New Phytol. 87:817-839.

Prentice, I.C. 1986. Vegetation responses to past clmatic variation. Vegetatio 67:131-141.

Prentice, I.C., W. Cramer, S.P. Harrison, R. Leemans, R.A. Monserud, and A.M. Solomon. 1992. A global biome model based on plant physiology and dominance, soil properties, and climate. J. Biogeography 19:117-134. 
Prentice, I.C., M.T. Sykes, and W. Cramer. 1993. A simulation model for the transient effects of climate change on forest landscapes. Ecological Modelling 65:51-70.

Rind, D., Goldberg, R., and Ruedy, R. 1989. Change in climate variability in the 21 st century. Climatic Change 14: 3-37.

Ritchie, J.C. 1986. Climate change and vegetation response. Vegetatio 67:65-74.

Roberts, L. 1989. How fast can trees migrate? Science 243:735-737.

Rowntree, P.R. 1985. Comment on 'Climate change and the broad-scale distribution of terrestrial ecosystem complexes' by Emanuel, Shugart, and Stevenson. Climatic Change 7:455-456.

Running, S.W. and R.R. Nemani. 1987. Extrapolation of synoptic meteorological data in mountainous terrain and its use for simulating forest evapotranspiration and photosynthesis. Canadian J. Forest Research 17:472-483.

Scuderi, L.A. 1993. A 2,000-year tree ring record of annual temperatures in the Sierra Nevada mountains. Science 259:1433-1436.

Sharpe, P.J.H., J. Walker, L.K. Penridge, H.Wu, and E.J. Rykiel. 1986. Spatial considerations in physiological models of tree growth. Tree Physiology 2:403-421.

Shugart, H.H. 1984. A Theory of Forest Dynamics. Springer-Verlag, N.Y.

Shugart, H.H., T.M. Smith, and W.M. Post. 1992. The potential for application of individual-based simulation models for assessing the effects of global change. Annual Review Ecology and Systematics 23:15-38.

Smith, J.B., and D. Tirpak. 1989. The Potential Effects of Global Climate Change on the United States. U.S. Environmental Protection Agency, Washington, D.C.

Solomon, A.M. 1986. Transient response of forests to $\mathrm{CO}_{2}$-induced climate change: Simulation experiments in eastern North America. Oecologia 68:567-579.

Solomon, A.M., and P.J. Bartlein. 1992. Past and future climate change: Response by mixed deciduous-coniferous forest ecosystems in northern Michigan. Canadian J. Forest Research 22:1727-1738.

Solomon, A.M., and H.H. Shugart (eds.). 1993. Vegetation Dynamics and Global Change. Chapman and Hall, New York.

Solomon, A.M., and T. Webb. 1985. Computer-aided reconstruction of late-quaternary landscape dynamics. Annual Review Ecology Systematics 16:63-84.

Solomon, A.M., D.C. West, and J.A. Solomon. 1981. Simulating the role of climate change and species immigration in forest succession. p. 154-177. in West, D.C., H.H. Shugart, and D.B. Botkin. Forest Succession: Concepts and Applications. Springer-Verlag, New York.

Stahle, D.W., and M.K. Cleaveland. 1992. Reconstruction and analysis of spring rainfall over the southeastern U.S. for the past 1,000 yr. Bulletin of the American Meteorological Society 73:19471961. 
Stocker, T.F., and L.A. Mysak. 1992. Climatic fluctuations on the century time scale: A review of high-resolution proxy data and possible mechanisms. Climatic Change 20:227-250.

Swetnam, T.W. 1993. Fire history and climate change in Giant Sequoia groves. Science 262: 885-889.

Swetnam, T.W., and A.M. Lynch. 1993. Multicentry, regional-scale patterns of western spruce budworm outbreaks. Ecological Monographs 63:399-424.

Urban, D. L., and H.H. Shugart. 1989. Forest response to climate change: A simulation study for southeastern forests. pp. 3-1 to 3-45. in J.B. Smith and D. Tirpak (eds.). The Potential Effects of Global Climate Change on the United States. U.S. Environmental Protection Agency, Washington, D.C.

Urban, D.L., M.E. Harmon, and C.B. Halpern. 1993. Potential response of Pacific Northwestern forests to climatic change, effects of stand age and initial composition. Climatic Change 23:247-266.

Vogt, K.A., Vogt, D.J., Moore, E.E., Fatuga, B.A., Redlin, M.R., and Edmonds, R.L. 1987. Conifer and angiosperm fine-root biomass in relation to stand age and site productivity in Douglas-fir forests. J. Ecology 75:857-870.

Waggoner, P.E. 1989. Anticipating the frequency distribution of precipitation if climate change alters its mean. Agricultural and Forest Meteorology 47:321-337.

Watts, W.A., B.C.S. Hansen, and E.C. Grimm. 1992. Camel Lake: A 40,000-yr record of vegetational and forest history from northwest Florida. Ecology 73:1056-1066.

Webb, T., III. 1981. The past 11,000 years of vegetational change in eastern North America. BioScience 31:501-506.

Webb, T., III. 1986. Is vegetation in equilibrium with climate? How to interpret late-Quaternary pollen data. Vegetatio 67:75-91.

Webb, T., III. 1992. Past changes in vegetation and climate: Lessons for the future. pp. 59-75. in R.L. Peters and T.E. Lovejoy (eds.). Global Warming and Biological Diversity. Yale University Press, New Haven, Conn.

Woodward, F.I. 1992. A review of the effects of climate on vegetation: Ranges, competition, and composition. pp. 105-123. in R.L. Peters and T.E. Lovejoy (eds.). Global Warming and Biological Diversity. Yale University Press, New Haven, Conn.

Wright, J.W. 1976. Introduction to Forest Genetics. Academic Press, New York.

Zabinski, C., and M.B. Davis. 1989. Hard times ahead for Great Lakes forests: A climate threshold model predicts responses to $\mathrm{CO}_{2}$-induced climate change. pp. 5-1 to 5-19. in Smith, J.B. and D. Tirpak (eds.). The Potential Effects of Global Climate Change on the United States. U.S. Environmental Protection Agency, Washington, D.C. 


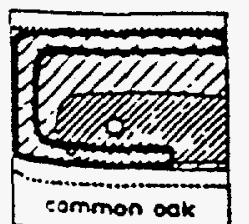

sommon ook

Duercus robur

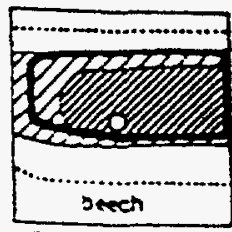

Fogus syivatico

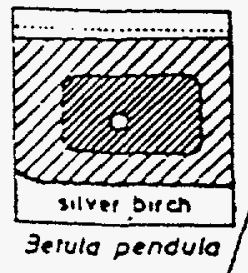

dominance $t$ ange

needle trees

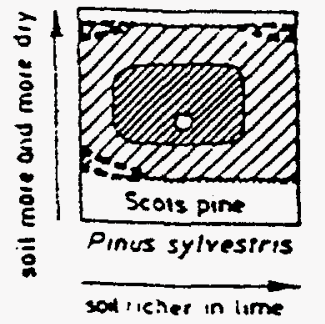

soiticher in lime

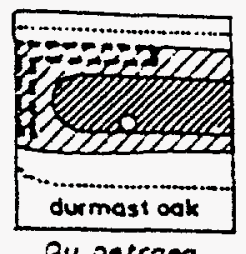

Ou petraea

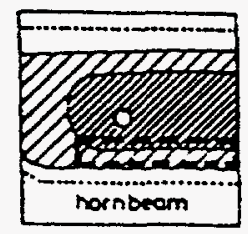

Corainus betulus
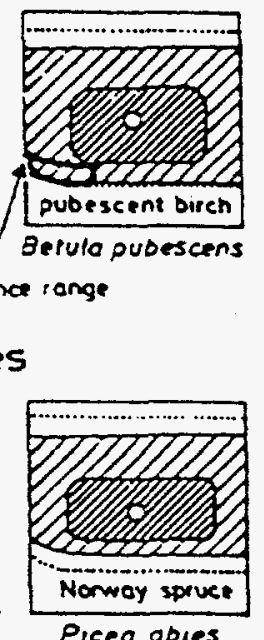

Picea abies

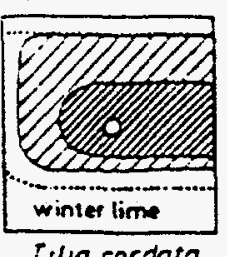

rilia cordata

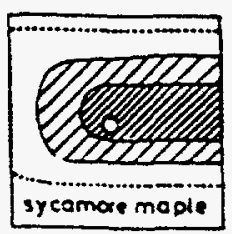

Acer sefucholatons

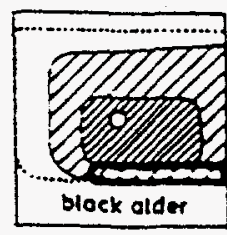

Alnus glutinoso

potential ronge

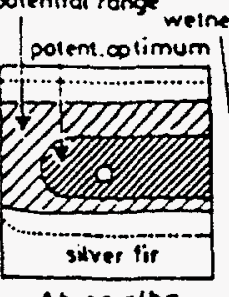

abies alba
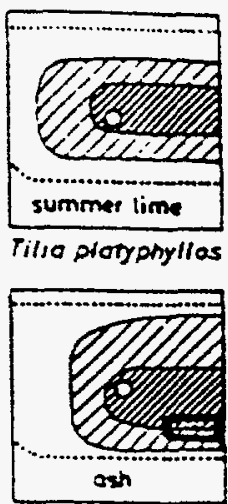

Frazinus excrisior

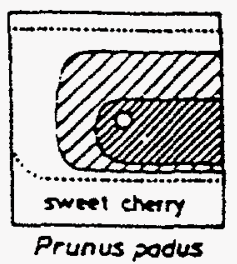

Prunus podus

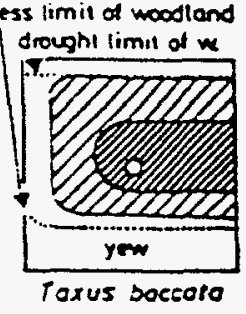

Figure 1. Fundamental versus realized niche breadth (from Ellenberg 1988 by permission) for trees in the central Europe submontane belt under temperate oceanic climates. In each of the ecograms the ordinate represents the degree of wetness of the habitat (from open water through soils of decreasing wetness to shallow soils above rock exposed to the sun, which lose all moisture in drought periods). The abscissa covers the range from extremely acid to lime-rich soils. Above the upper dotted line it is too dry for any tree growth; below the lower one it is too wet. The small circle in the center of the ecogram indicates the average conditions. All trees would flourish here, but only the beech prevails under natural conditions of competition. 

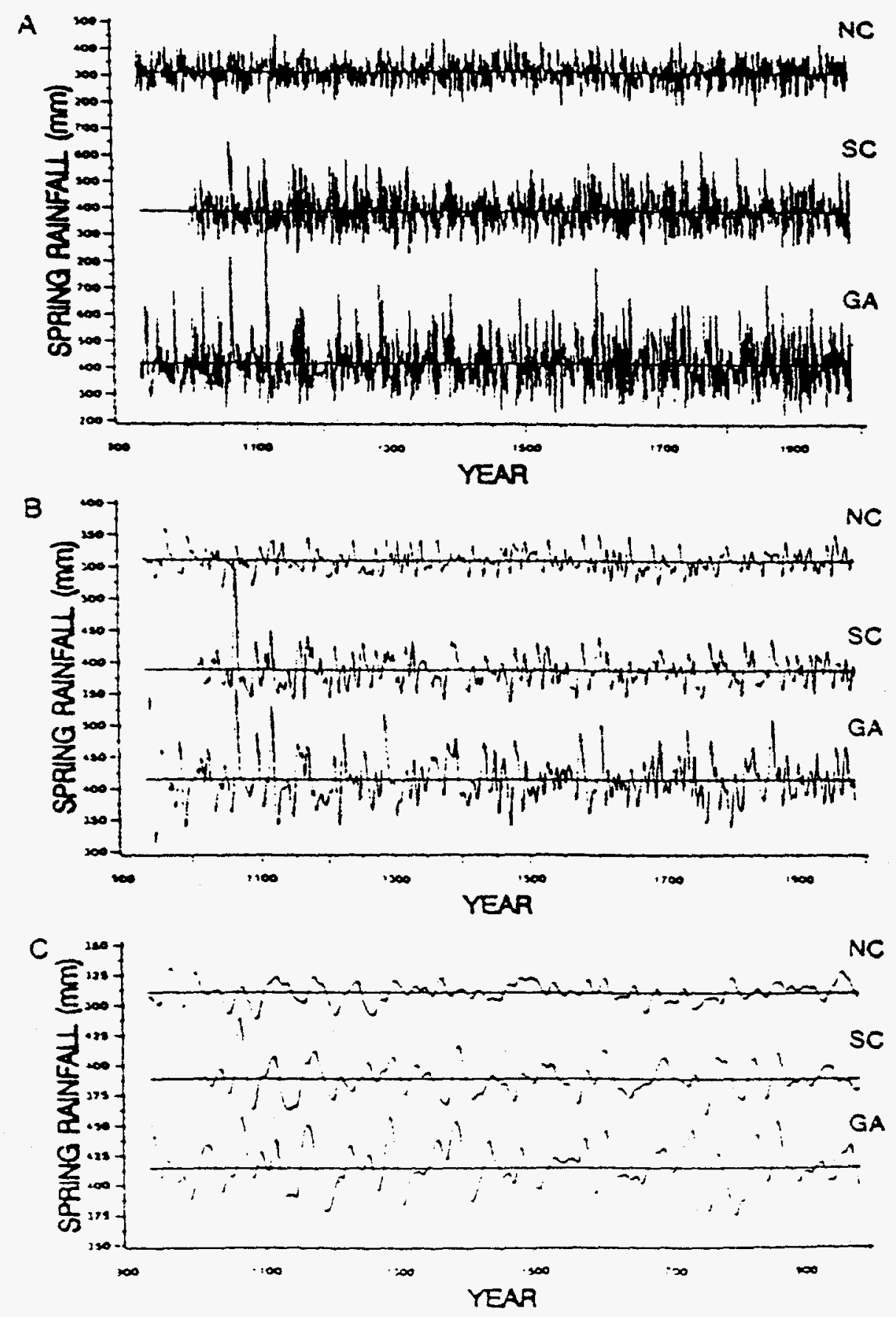

Figure 2. Reconstructed annual rainfall data (a) for bald cypress (from Stahle and Cleaveland 1992 by permission). Each rainfall reconstruction was smoothed with cubic smoothing splines designed to reduce $50 \%$ of the variance in a sine wave with a period of 10 years $(b)$ and 30 years $(c)$. Note the interval and labeling differences on the $y$-axes in $(a),(b)$, and $(c)$. 


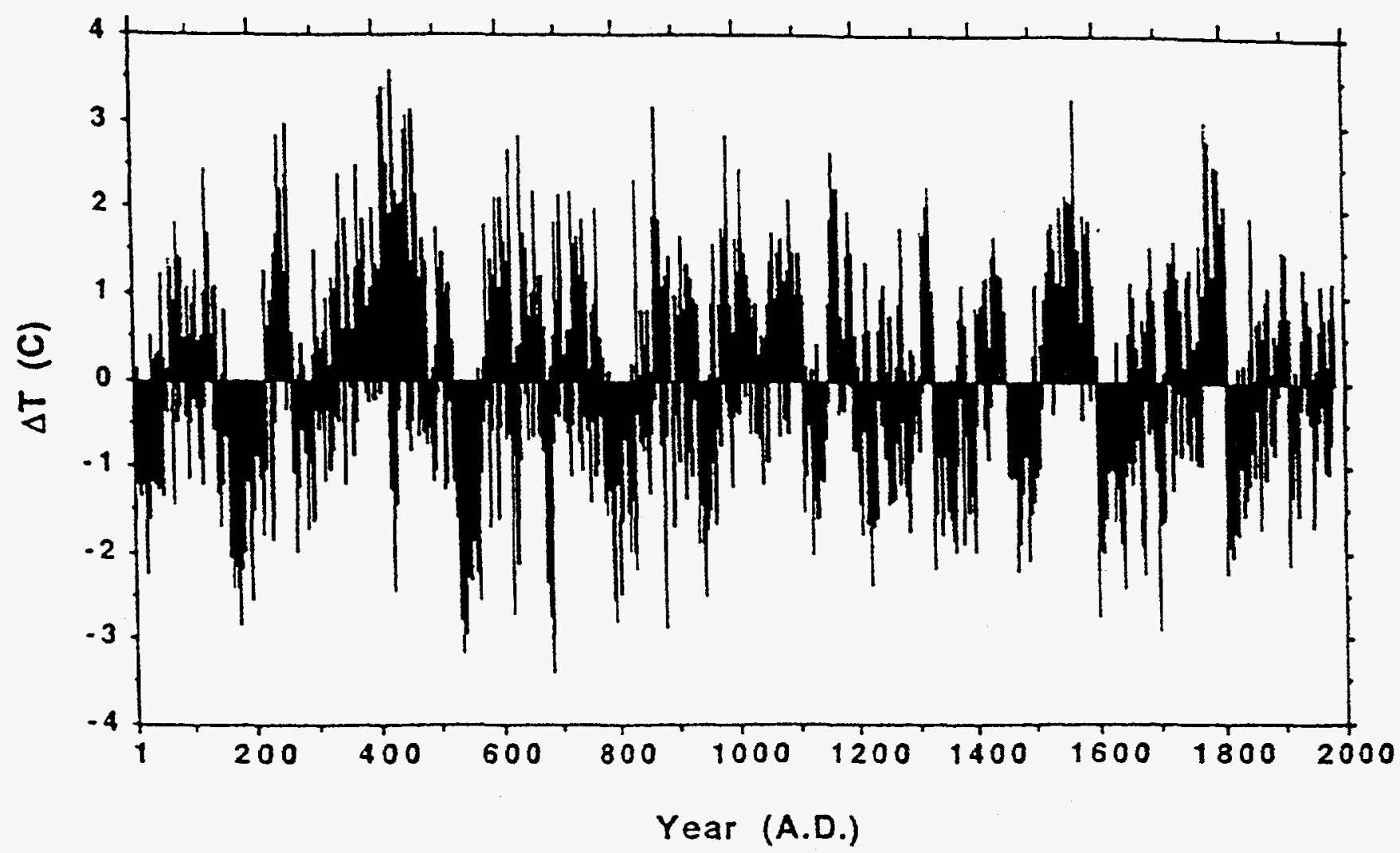

Figure 3. Reconstructed June through January temperature anomalies for southern Sierra Nevada relative to the A.D. 1 to 1980 mean. The A.D. 1951 to 1970 reference temperature is $0.12^{\circ} \mathrm{C}$ above the long-term mean (from Scuderi 1993 by permission). 


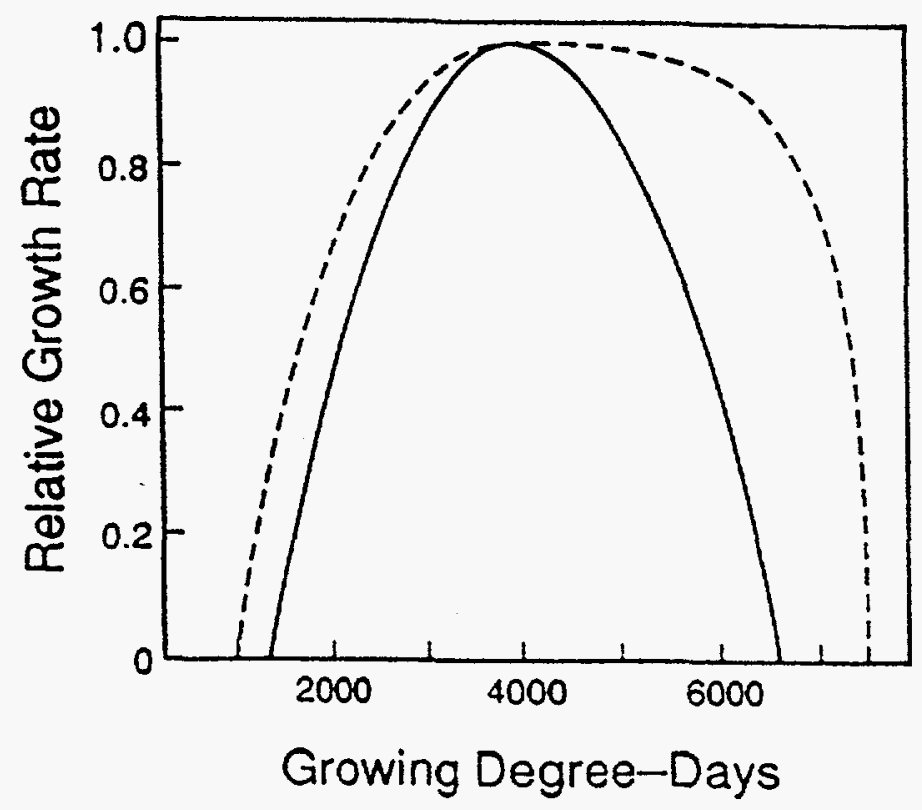

Figure 4. Temperature-response function. Solid line is that used in current models; dashed line is that proposed $u$ represent the fundamental niche. 


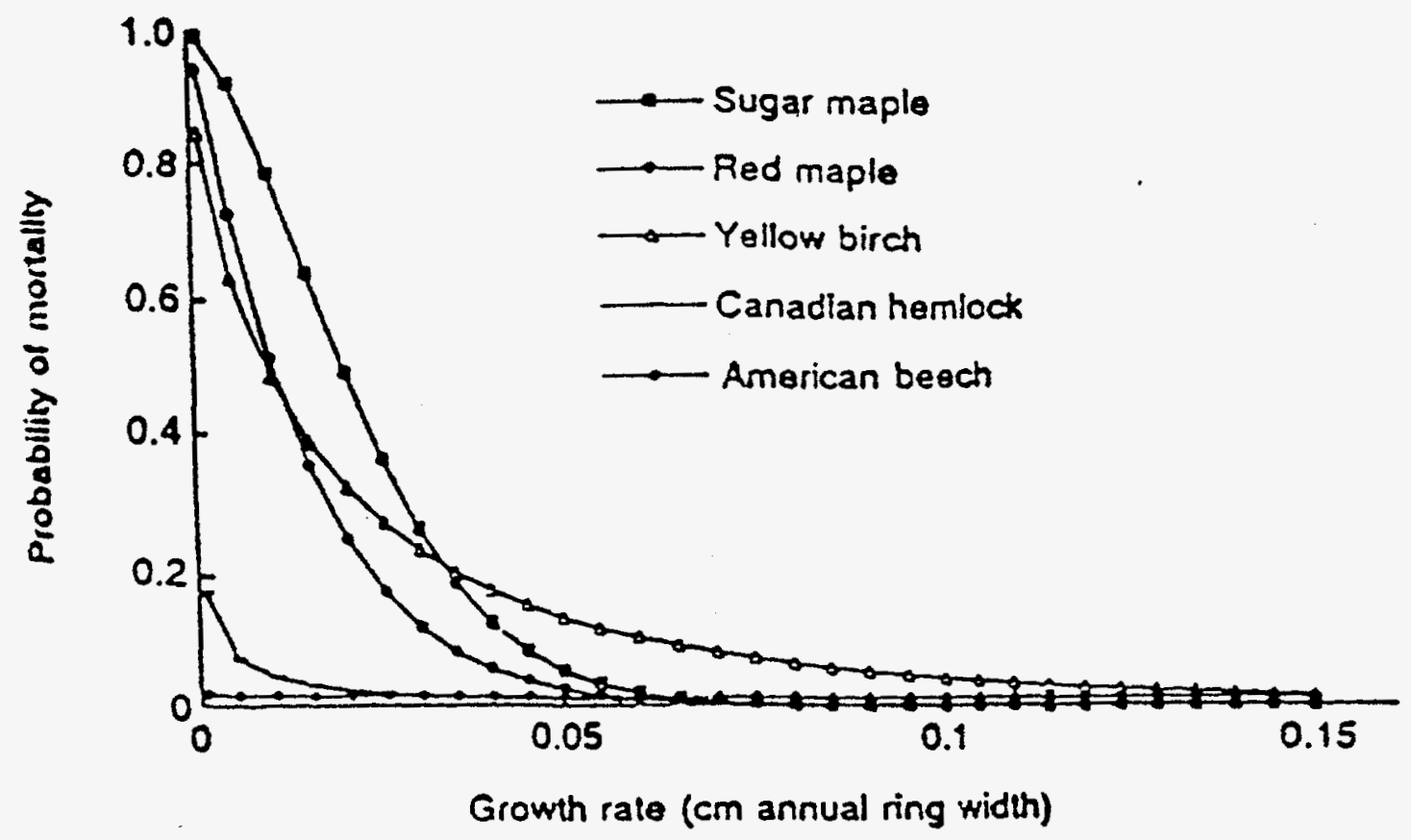

Figure 5. Mortality-response functions (from Pacala and Hurtt 1993 by permission). 


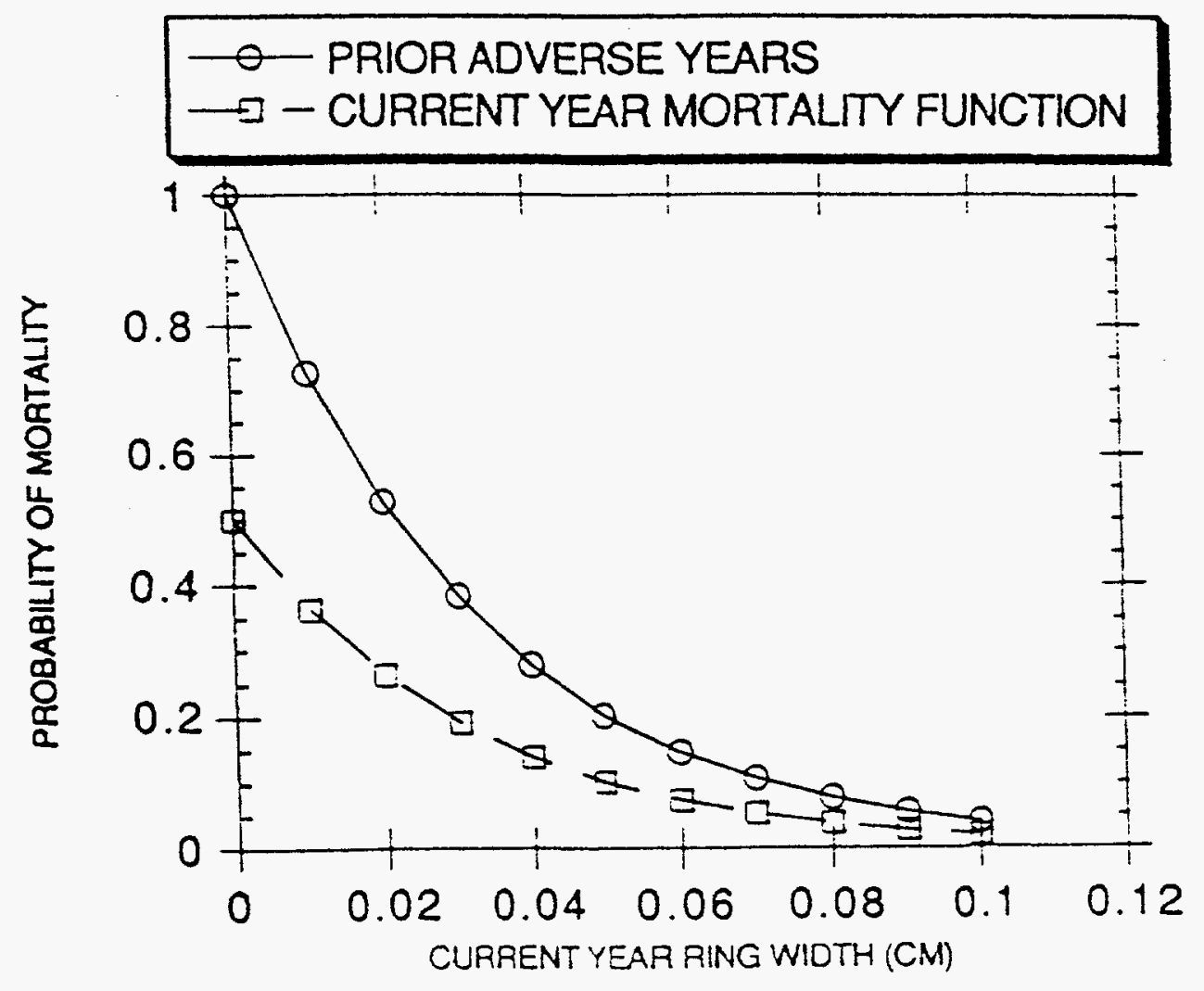

Figure 6. Modified mortality function that takes into consideration time period of growth suppression. 